\title{
Perspectives on ecosystem-based approaches to the management of marine resources
}

\author{
Idea and coordination: Howard I. Browman, Konstantinos I. Stergiou \\ Contributors*: Howard I. Browman, Philippe M. Cury, Ray Hilborn, Simon Jennings, Heike K. Lotze, \\ Pamela M. Mace, Steven Murawski, Daniel Pauly, Michael Sissenwine, Konstantinos I. Stergiou, Dirk Zeller
}

\section{Introduction}

\author{
Howard I. Browman ${ }^{1, * *}$, Konstantinos I. Stergiou ${ }^{2}$ \\ ${ }^{1}$ Institute of Marine Research - Austevoll, 5392 Storebø, Norway \\ Email: howard.browman@imr.no \\ ${ }^{2}$ Aristotle University of Thessaloniki, School of Biology, \\ Department of Zoology, Box 134, Thessaloniki 54124, Greece \\ Email: kstergio@bio.auth.gr
}

The urgent need to reduce the intense pressure and destructive power that modern fishing practices apply to the world's fisheries, and the oceans that support them, is now widely recognized (e.g. FAO 2002a, Hilborn et al. 2003). However, there is far less agreement over the exact levels to which fishing mortality must be reduced and over how to reduce the indirect effects of fishing (e.g. bycatch, destruction of the seafloor), in order to ensure sustainability of catches and the health of marine ecosystems. And this is to say nothing of disagreements over how these goals might be achieved. It has proven all too easy for various factions - including some fishery scientists - to blame our having arrived at the current crossroads on the ineffectiveness of existing management practices, and on the scientific advice that underlies it. Driven by these forces, and in recognition of the significant direct and collateral impacts that fishing imposes on marine ecosystems, an Ecosystem Approach to Fisheries (EAF) is rapidly being adopted by institutions charged with stewardship of the marine environment (e.g. NOAA 1999, Brodziak \& Link 2002, FAO 2003, Garcia et al. 2003, Sinclair \& Valdimarsson 2003). In conjunction with this EAF is the implementation of Marine Protected Areas (MPAs), including marine reserves. Both EAF and MPAs implicitly recognize that the value (to humanity) of the whole ecosystem is much greater

\footnotetext{
${ }^{*}$ Contributions are presented in alphabetical order (by first author)

** The views expressed here are those of the author only and do not necessarily reflect the official position of The Institute of Marine Research
}

than the sum of its parts - a commendable step forward in-and-of itself. However, there is some disagreement over whether the EAF, and MPAs, truly represent alternatives that will be any more effective in assisting us with sustainable management of marine resources than historical practices. Regardless of the approach that is taken to decide upon catch limits, or on the location, size and number of MPAs, there will always be the complicated (and socio-economically-politically charged) question of how these policies should be implemented and enforced; that is, governance (see, for example, Mace 2001, Sissenwine \& Mace 2003, Caddy 2004, Cochrane 2004, Stefansson 2004). To address these issues, we solicited essay-style contributions from several of the marine and fishery scientists who are at the forefront of the ongoing debate. Those essays are presented here.

We will not use space summarizing the content of this Theme Section (TS) - we encourage you to read through it. Rather, we take this opportunity to highlight some of the most important conclusions that issue from the essays when they are taken as a whole and to add some commentary of our own. The acronyms used in this TS are listed in Table 1.

In the critical recommendation of such fishery management tools as limits on maximum fishing mortality, minimum spawning stock biomass, or total allowable catch levels, fishery scientists often disagree about seemingly subtle (to the layman) aspects of data analysis and interpretation. Although debates such as these are at the core of the scientific process, the fact that fishery scientists themselves do not always agree has been the focus of socio-political criticism, and is surely one of the reasons that advice on catch quotas is not often strictly heeded. In the case of the contributions to this TS, written by proponents sitting on both sides of the fence, there is a convincing consensus on most of the key issues. While there is disagreement over just

(C) Inter-Research $2004 \cdot$ www.int-res.com

Resale or republication not permitted without written consent of the publisher 
how severely depleted some fish stocks are, and on whether and how quickly they will recover, all agree that many stocks are overexploited. While there is some disagreement over just how much fishing must be reduced, all agree that current levels of overcapacity in the world's fishing fleets are not sustainable. While there is disagreement over equating MPAs and $\mathrm{EAF}$, all agree that MPAs will complement other management tools, within an EAF or not. Thus, for each and every major issue, while there might be disagreement on the details, there is unanimity over the pressing need for action to protect marine ecosystems. And that must be made the focus of public attention.

Iles (1980) refers to '... a 'Bio-Energetic Multi-Species Ecosystem Dynamics (BEMUSED)... ' basis for setting catch quotas. This illustrates how the idea of taking an EAF is really nothing new, and it highlights that, unless we are truly more clever (and richer with data) than we were almost $25 \mathrm{yr}$ ago, following EAF could leave us just as bemused, and/or muddled (see Hedgpeth 1977). Iles (1980) also stated that '.... social, politi$\mathrm{cal}$, and economic factors are at least as important in fisheries management as the scientific knowledge of the resource.' This conclusion, arrived at $24 \mathrm{yr}$ ago, is reiterated by several contributors to this TS-governance, and not science, remains the weakest link in the management chain (also see Hutchings et al. 1997, Harris 1998, Policansky 1998, FAO 2003, Cochrane 2004). Thus, even if we were able to provide managers with perfect scientific prediction, that alone will not help. Following from all of this, if there is any hope of succeeding with an EAF, or any real chance of controlling fishing, the organizations and institutions involved in the governance of marine resources will have to be totally revamped. The new structure will have to include stakeholders, social and political scientists, economists, lawyers, political lobbyists, educators, journalists, civil engineers, ecologists, fishery scientists and oceanographers, all operating in a conciliatory and integrative environment.

We hope that the following analogy will illustrate that it is untenable to ignore the counsel of fishery scientists, even when they disagree and/or provide advice that is based upon highly uncertain assessments (also see Stefansson 2004). If meteorologists say that a major storm is coming, people are relocated to safer places, and houses and buildings are boarded up. Even if the predictions about when and where the storm will hit-provided by extensive networks of expensive ground-based monitoring devices and weather satellites - are not very accurate (because the storm's behaviour is unpredictable), precautions are still taken, often over a very wide geographic area... just in case. This illustrates that society does not expect meteorologists to predict the weather with any degree of accuracy, yet we have somehow all learned to live with that, and take appropriate precautions nonetheless. In the face of this analogy, we must ask: why does society have higher expectations of fishery scientists with respect to their ability to accurately predict the numbers of fish that will be in the sea several years into the future? Further, why is it so difficult for fishery scientists to convince society, authorities, and stakeholders to take a precautionary approach towards the management and conservation of fish stocks (or whole ecosystems) (see Lotze's contribution to this TS)? Finally, if people are routinely relocated to a safe place when a potentially destructive storm is coming, why is it so difficult to recognize the inherent rights that marine fauna have to a safe haven (in the form, for example, of MPAs)? The international treaty represented by the Montreal Protocol on Substances that Deplete the Ozone Layer is another example of how society can respond when the stakes are high and the need is urgent: society can adopt and implement precautionary approaches to the management of the world's resources, even when there are complex mixtures of stake holders. Hopefully, we will be able to achieve the same for the world's marine ecosystems.

Table 1. Acronyms and their full forms used in the TS

\begin{tabular}{|c|c|}
\hline $\begin{array}{l}\text { Abbreviation/ } \\
\text { acronym }\end{array}$ & Full name \\
\hline BEMUSED & $\begin{array}{l}\text { Bio-Energetic Multi Species Ecosystem } \\
\text { Dynamics }\end{array}$ \\
\hline CML & Census of Marine Life \\
\hline EAF & Ecosystem Approach to Fisheries \\
\hline EEZ & Exclusive Economic Zones \\
\hline FAO & Food and Agriculture Organization \\
\hline GIS & Geographic Information System \\
\hline GLOBEC & Global Ocean Ecosystem Dynamic Programs \\
\hline GOOS & Global Ocean Observing System \\
\hline ICES & $\begin{array}{l}\text { International Council for the Exploration of } \\
\text { the Sea }\end{array}$ \\
\hline ICNAF & $\begin{array}{l}\text { International Convention for the Northwest } \\
\text { Atlantic Fisheries }\end{array}$ \\
\hline ITQ & Individual Transferable Quotas \\
\hline IUCN & $\begin{array}{l}\text { International Union for the Conservation of } \\
\text { Nature }\end{array}$ \\
\hline LME & Large Marine Ecosystem \\
\hline MPA & Marine Protected Areas \\
\hline MSY & Maximum Sustainable Yield \\
\hline MVH & Member-Vagrant Hypothesis \\
\hline NOAA & $\begin{array}{l}\text { National Oceanic and Atmospheric } \\
\text { Administration }\end{array}$ \\
\hline OECD & $\begin{array}{l}\text { Organisation for Economic Co-operation and } \\
\text { Development }\end{array}$ \\
\hline PISCO & $\begin{array}{l}\text { Partnership for Interdisciplinary Studies of } \\
\text { Coastal Oceans }\end{array}$ \\
\hline UNDP & United Nations Development Plan \\
\hline UNEP & United Nations Environmental Programme \\
\hline TAC & Total Allowable Catch \\
\hline
\end{tabular}




\section{Marine Protected Areas as a central element of ecosystem-based management: defining their location, size and number}

\author{
Howard I. Browman ${ }^{1, *}$, Konstantinos I. Stergiou ${ }^{2}$ \\ ${ }^{1}$ Institute of Marine Research - Austevoll, 5392 Storebø, Norway \\ Email: howard.browman@imr.no \\ ${ }^{2}$ Aristotle University of Thessaloniki, School of Biology, \\ Department of Zoology, Box 134, Thessaloniki 54124, Greece \\ Email: kstergio@bio.auth.gr
}

Marine Protected Areas (MPAs) include many subclasses (e.g. marine sanctuaries, marine parks, wildlife refuges, fisheries closures, no-take MPAs, multiple-use MPAs, marine reserves, ecological reserves) all of which can be defined based mainly upon the level of protection and the primary conservation goal (see www.mpa.gov; Lubchenco et al. 2003). MPAs, and especially the marine reserves subclass (i.e. 'areas of the ocean completely protected from all extractive and destructive activities'; Lubchenco et al. 2003) represent the extreme case of the precautionary approach to managing marine resources (e.g. Lauck et al. 1998).

The strong and rapidly growing interest in MPAs (and particularly in marine reserves) is reflected in the dramatic increase in the number of publications devoted to them (reviewed in Jones 2002, Gell \& Roberts 2003, and the articles in 'The Science of Marine Reserves', a supplemental issue of Ecological Applications, Vol 13, Iss 1, freely available for download at www.esa-journals.org/esaonline/?request=getstatic\&name $=$ s1051-0761-013-01-0001). In addition, there are now a number of sites on the World Wide Web that are either totally devoted to MPAs, or include relevant information on them: UNEP's World Conservation Monitoring Centre (www.unep-wcmc.org/ protected_areas), the Partnership for Interdisciplinary Studies of Coastal Oceans (PISCO, www. piscoweb.org), and several others. This intense interest is at least partly related to MPAs having been identified and advocated as a conservation (of habitat and biodiversity) and managerial (of fisheries) tool of central importance in the Ecosystem Approach to Fisheries (EAF) (e.g. Agardy 2000, Stergiou 2002, Halpern \& Warner 2003, Lubchenko et al. 2003, Pauly \& MacLean 2003, Hilborn et al. 2004). It is hoped that MPAs will be beneficial in (1) rebuilding overexploited fish stocks, (2) preserving habitat and biodiversity, (3) maintaining ecosystem structure, (4) buffering against the effects of environmental variability, (5) serving as a control group against which populations in exploited regions can be

*The views expressed here are those of the author only and do not necessarily reflect the official position of The Institute of Marine Research compared, among others. Clearly, the choice of location, spatial extent (horizontal and vertical), and number of MPAs is critical if they are to meet these goals. It is to this issue that we devote our attention here.

Halpern \& Warner (2003) state, 'Most reserve locations and boundaries were drawn by a political process that focused on economics, logistics, or public acceptance, while largely overlooking or ignoring how the complex ecology and biology of an area might be affected by reserve protection.' In this sense, establishing the locations and boundaries of MPAs can be seen as analogous to the imperfect process associated with establishing stock management grids - a process that has never really managed to incorporate the key realities of population dynamics of the exploited species. While there is a growing consensus on the need for MPAs, at this point in time there is no clear and well-founded basis upon which their location, spatial extent and number can be decided. In fact, rationales/frameworks that are based upon principles of theoretical and applied ecology have only recently been tapped to address these key questions (e.g. Roff \& Evans 2002, Botsford et al. 2003, Roberts et al. 2003a,b, Shanks et al. 2003, Fisher \& Frank 2004). Much of this work focuses on the manner in which different aspects of the life histories of marine organisms - spawning locations, dispersal, larval retention and export, juvenile nursery areas, etc.-affect MPA design. In this context, we contend that an ecoevolutionary framework already exists, grounded in marine ecology and fisheries oceanography, that is completely consistent with EAF and MPA objectives.

The Member-Vagrant Hypothesis as a framework for defining the location, size and number of MPAs. The Member-Vagrant Hypothesis (MVH), the development of which can be traced through a series of publications by Mike Sinclair and Derek Iles (Iles \& Sinclair 1982, Sinclair 1988, 1992, Sinclair \& Iles 1988, 1989), defines 4 attributes of populations that are involved in the regulation of their size. The 'population richness' refers to the number of discrete self-sustaining populations (henceforth simply 'populations') exhibited by any given species. Species such as herring, cod, mackerel, the salmonids, and many others are population rich. The 'spatial pattern' relates to the geographic distribution of these populations. Population rich species are usually also broadly distributed (the north Atlantic region is so far the best studied in this regard). Population richness and spatial pattern are species-level characters. The 'absolute abundance' refers to the instantaneous size of the various populations of any given species, and this size-which can range over several orders of magnitude-varies over time (thus, its 'temporal variability'). These last 2 components of the MVH are population-level characteristics. Sinclair \& Iles have applied the MVH to describe the richness, pattern, abundance and variability of several economically im- 
portant fish including herring, cod, haddock, mackerel, and several others. For all of these, (1) the population richness is directly correlated with the number of retention areas for the species' early life history stages (also implying that the adults are able to return to the same geographic locations); (2) the spatial pattern is related to the number of discrete geographic areas allowing closure of the species' life cycle; (3) the absolute abundance is scaled according to the size of the geographic area in which there is closure of the life cycle (corroborated by MacKenzie et al. [2003], who reported that the biomass of cod spawners and recruits is related to habitat size); (4) the geographic locations referred to in (1), (2) and (3) have distinct oceanographic features; and (5) the temporal variability is determined by the intergenerational losses of individuals from any one population (through mortality and/or passive processes such as advection or spatial constraints = 'vagrancy'). It is worth noting that the $\mathrm{MVH}$ is completely consistent with the metapopulation concepts that have recently been applied to marine fish populations (e.g. Smedbol \& Wroblewski 2002)

Exploited populations are subject to intense sizedependent mortality and drastic reductions in biomass over a short time and a large spatial scale (e.g. Christensen et al. 2003, Myers \& Worm 2003, Pauly \& MacLean 2003). With modern fishing practices and equipment, this can impact a large proportion of the populations in a species' entire spatial pattern. Thus, commercial fishing imposes new conditions on these populations and, therefore, drastically affects all $4 \mathrm{MVH}$ population attributes.

The MVH ' ...emphasizes that membership in a population in the oceans requires being in the appropriate place during the various parts of the life cycle. It implies that animals can be lost from their population, and thus become vagrants. Life cycles are considered as continuity solutions within particular geographical settings which impose spatial constraints.' (Sinclair \& Iles 1989, p. 169). Thus, for many marine fishes, population richness, pattern, absolute abundance and temporal variability are all a function of geography.

Following from the MVH, the location of MPAs should be chosen to include a subset of the populations within a species' (or species complex) spatial pattern. The size of each such MPA would then be assigned based upon the geographic area within which the corresponding population's life history can achieve closure. In our view, applying the MVH in this manner would satisfy many of the objectives of MPAs.

It has only recently been possible to assess whether MPAs do in fact provide the benefits listed above (reviewed in e.g. S. J. Hall 1998, Jones 2002, Gell \& Roberts 2003, Halpern \& Warner 2003, Luchenco et al. 2003, Hilborn et al. 2004). These assessments have led to arguments over the degree to which MPAs can or will succeed. There is also some concern over the possibility of an im- balanced reliance upon MPAs as a fisheries management tool (see Hilborn et al. 2004 and several of the contributions to this TS). Nonetheless, if the choice of their location, size and number is well grounded in marine ecology and fisheries oceanography, then MPAs stand to become an effective tool for conservation and management. In order for this to be realized, 2 closely related steps are required. First, an operational spatial unit within which MPAs will be embedded must be defined. Such a unit already exists: the Large Marine Ecosystem (LME) (e.g. Sherman \& Duda 1998). LMEs are large 'regions of ocean space encompassing coastal areas from river basins and estuaries to the seaward boundaries of continental shelves and the outer margins of the major current systems' characterized by 'distinct: (1) bathymetry, (2) hydrography, (3) productivity, and (4) trophically dependent populations' (www.lme.noaa.gov). When combined with Longhurst's (1998) 'Biogeochemical Provinces', which extend out into the open ocean areas, LMEs can provide a very useful ecosystem framework for fisheries research (see Pauly \& MacLean 2003, www.seaaroundus.org). Second, future work in fisheries science could adopt a more ecological/oceanographic orientation, by (1) identifying and mapping the key faunistic components and the biodiversity 'hot spots' (sensu Worm et al. 2003) in the main ecosystems of the world's oceans (as defined above); (2) describing the life cycles of these key components within the context of the MVH framework; (3) spatially mapping the life cycles of key species (see Zeller \& Pauly 2001); and (4) identifying the special oceanographic features associated with the retention and nursery areas of these key components (recent work linking population genetics with marine ecology and fisheries oceanography holds promise in this regard, e.g. Reiss et al. 2000).

Acknowledgements. For their influences on our development as marine scientists, we dedicate this essay to Maxwell J. Dunbar (deceased), T. Derek Iles, William C. Leggett, Brian M. Marcotte and Michael Sinclair. We thank K. Erzini, K. T. Frank, J. J Govoni, and D. Pauly for their comments on the manuscript. H.I.B.'s ongoing research, and his editorial activity for MEPS, is supported by the Institute of Marine Research, Norway, and by The Research Council of Norway.

\section{Tuning the ecoscope for the Ecosystem Approach to Fisheries}

\author{
Philippe M. Cury
}

Institut de Recherche pour le Développement (IRD), CRHMT BP 171, 34203 Sète Cedex, France Email: philippe.cury@ird.fr

A multidisciplinary scientific approach is needed for the Ecosystem Approach to Fisheries (EAF). The Reykjavik Declaration of 2001, reinforced at the World 
Summit of Sustainable Development in Johannesburg in 2002, requires nations to base policy related to marine resource exploitation on an ecosystem approach. To fulfil this new requirement, a strategy based upon innovative science that will address the complexity of marine ecosystems, coupled with operational frameworks for an effective EAF is needed. EAF must be built on a scientific rationale that will link ecological processes to ecosystem-level patterns. In doing so, it will help managers to recognize and understand ecological limits to avoid the loss of ecosystem integrity and to maintain fisheries in viable states (Fowler \& Hobbs 2002, Mullon et al. 2004).

This is a challenging task, as marine ecosystems are difficult to define, having no apparent boundaries, and lacking the clear objective or purpose that can be ascribed to more tractable biological or ecological entities (e.g. individuals or populations). An ecosystem contains water, nutrients, detritus, and numerous kinds and sizes of organisms ranging from bacteria, phytoplankton, zooplankton, and fish to mammals and birds, all with their own life history traits. These living and non-living ecosystem components are interconnected through continuously changing food webs, which make ecological systems extraordinarily complex.

Today, the explicit study of complexity is both necessary and timely in ecology (Loehle 2004). Emergence has replaced the earlier mostly theoretical approach to implementing classical population dynamics in ecology (Woods 2004). The concept of simple cause and effect is neither adequate nor sufficient when dealing with complex systems, particularly if one accepts the principle that prediction is a pre-requisite for applied ecological research (Peters 1991). Research in ecology has been based mostly on studying processes in detail, resulting in an impressive number of potential causeeffect relationships to explain emergent patterns. Emerging patterns suggest likely tendencies and possible response trajectories. A combination of the process and emergence approaches has long been advocated (Elton 1927), but with relatively little success, despite its promise of ameliorating our understanding of marine ecosystems.

Many tools, information systems and models have been developed, particularly during the last decade, such as coastal hydrodynamic models, individual-based models that couple physics and ecology, Geographic Information System (GIS) and ecosystem models. These various techniques, in many cases highly sophisticated, offer a unique opportunity in ecology to address the complexity of marine ecosystems in a diverse and contrasted manner. Despite the variety of techniques that can help track spatial and dynamical changes in ecosystems, it is often unclear, however, how these can be applied to solve specific scientific problems or to respond to questions of importance to society.

Using the telescope and microscope as analogies, the term 'ecoscope' was proposed by Ulanowicz (1993) to characterize ecosystem modelling that may be used as a tool for resolving patterns, indicative of the key ecosystem responses (that may otherwise be obscured within the complexity of marine ecosystems). Today there exists no general, unified theory of the functioning of marine ecosystems, nor a single tool on which a reliable 'ecoscope' can be based. Moreover, in the context of global changes (i.e. climate change and overexploitation), the exercise is even more difficult as we are facing changes and fluctuations on a global scale that have not been experienced before (Holling 1995). To respond to these challenges, the ecoscope must be operationalized into an integrative framework for studying marine ecosystems and responding to the needs of the EAF. I discuss below how we can start implementing this approach.

Linking patterns to processes. Strong ecological patterns have been described in marine ecosystems (Parson 2003). The mechanisms explaining alternation between different pelagic fish populations, synchrony between remote fish populations, and regime shifts still remains largely speculative in the marine environment contrary to studies in lake ecosystems (Carpenter 2003). I will use the example of regime shifts that represent a crucial ecological pattern for the EAF, as they are sudden changes in structure and functioning of marine ecosystems that affect several components, exploited or not. For example, shifts from demersal fish dominated to pelagic fish dominated ecosystems (or short-lived species such as shrimps, crabs or octopus) have been documented in the Atlantic and the Baltic (Worm \& Myers 2003); shifts from fish-dominated to jellyfish-dominated ecosystems have been observed in the Bering Sea, the Black Sea, the Gulf of Mexico, the western Mediterranean Sea, Tokyo Bay and off Namibia (Parsons \& Lalli 2002). These regime shifts have deeply modified marine ecosystems and the fisheries they sustain. EAF requires understanding the nature of such ecosystem changes, i.e. the processes that are involved, the speed at which they act, their potential reversibility and periodicity...

Linking processes to patterns. Regime shifts have been related mainly to climatic changes, but anthropogenic influences also play a major role in inducing ecosystem changes. A regime shift may be environmentally driven (e.g. through bottom-up control of the food web, or via direct effects on recruitment), ecologically driven (e.g. through competition, predation), mediated behaviourally (e.g. behavioural adaptations to habitat change) or driven by human exploitation of selected species or preferential fish size classes (Cury \& Shannon 2004). 
Environmental processes act at different scales and probably simultaneously affect most species within the ecosystem. Under bottom-up control, a major environmental change can alter the ecosystem's primary productivity and, thereby, the flow of energy to higher trophic levels. Climatic variability can itself trigger a series of concomitant physical and biological processes in the form of system wide 'regime shifts' (Hare \& Mantua 2000). Mesoscale events can trigger huge variability in pelagic fish recruitment success (Roy et al. 2001). In upwelling systems, a small number of pelagic fish species occupy the intermediate trophic level, feeding mostly on phytoplankton and/or zooplankton. These species can attain huge biomasses, which can vary radically depending upon the strength of the environmental factors driving recruitment. The role of dominant pelagic fish has been emphasized as they might exert major control on energy flow, both up and down the food web; this has been termed 'wasp-waist control' (Cury et al. 2000). Predation is a fundamental process that is sometimes as important as resource limitation in controlling ecosystem dynamics. As most fish species interact through predation, the existence of top-down control, through which the lower levels of the food web are regulated by 1 or several upper-level predators, appears to initiate trophic cascades in several marine ecosystems (Cury et al. 2003). Fisheries tend to remove top-down forces by preferentially exploiting large top predators in marine ecosystems, a mechanism known as 'fishing down the food web' (Pauly et al. 2000). This mechanism can result in an increase in the abundance of small forage fish (or short-living species) and to a stronger effect of climate on depleted marine resources (Beaugrand et al. 2003, Cury \& Shannon 2004). All of the processes that are associated with environmental or anthropogenic forces should be related in a more organized manner to the observed patterns of change in marine ecosystems. In order, for example, to arrive at a useful level of generalization, the respective roles of top-down, bottom-up or wasp-waist forces need further exploration.

The 'ecoscope' as a multidisciplinary dynamical tool to move towards an EAF. Theories, models, and observations of the patterns that are important for ecosystem dynamics need to be linked (Scheffer \& Carpenter 2003). Ecologists have been analyzing ecological interactions in 2 different, and often mutually exclusive, ways using reductionist (process-oriented) or holistic (pattern-oriented) approaches. However, as stated by Elton (1927), a combination of the 2 methods would be better. Seventy-five years later, this remains the approach that should be applied in future research on ecosystem dynamics. The ecoscope could be one such set of tools.
We need to encourage research in this direction and assemble processes and patterns in the same framework to explore the impact of global changes in time and space. The 'ecoscope' can be tuned to disentangle realities and speculations by assembling our present biological, ecological, modelling, and operational tools (GIS; indicators). The 'ecoscope' would not rely on a single model, but would incorporate a suite of models that can use different assumptions for depicting in a robust manner the relevant processes.

With the rapid development of models, methods and hypotheses, there already exists a large variety of complementary approaches and tools. The 'ecoscope' encompasses all of our expertise and knowledge on marine ecosystems; however, it needs to be built around key scientific questions and information systems. Global changes that affect marine ecosystems, such as overexploitation and climate change, are relevant scientific problems and effectively addressing these is crucial for sustainable development. Spatial and temporal dynamics that link the different organisational levels need to be tackled in any EAF. Dynamical information systems should represent the converging point around which specific questions can be raised and discussed within the different disciplines. It is a stimulating task for the future, as it requires macroecological studies of the oceans to characterize patterns of ecosystem components, based on large amounts of data (Parsons 2003). A suite of field, experimental and modelling approaches is required to identify, with a high degree of confidence, the underlying processes and emergent patterns. Gathering of fisheries and ecosystem data has, to date, mostly been undertaken separately and by different sub-groups of marine scientists, with little exchange. Long-term data series are needed to develop data banks for ecological and climatologically quality control. We also necessitate developing new observation systems by recognizing that ecological and biological data that are collected for single-species fisheries management are necessary but insufficient for understanding ecosystem dynamics. Ecosystem-based indicators can simplify, quantify and inform about the complexity of marine ecosystems. The elaboration and evaluation of ecosystem-based indicators - such as the Fishing-in-Balance index (Pauly et al. 2000) or those related to size spectra (Shin \& Cury 2004)-pertain to a multidisciplinary field of research on the marine ecosystem and may constitute a central focus for fisheries management. This represents a new framework that would challenge the difficulties of understanding the dynamics of complex systems at appropriate scales by enabling repeatable patterns to be tracked by indicators, and by incorporating existing scientific knowledge on processes into models and ultimately into fisheries management. 
The ecoscope for EAF should rely on 3 complementary components: (1) a clear identification of the long-term objectives (what we want and do not want to happen in marine ecosystems and for the exploitation of marine resources); (2) a multidisciplinary scientific expertise (data, theory, experiments, models) to address the impact of global changes on marine ecosystems, and that is articulated around dynamical information systems, such as maps and indicators, to stimulate interactions between disciplines; and (3) an evaluation of the performance of the ecoscope to solve scientific questions and to address management objectives for the EAF.

Building ecoscopes is a demanding way of integrating knowledge and the necessary 'ingredients' and tools to begin the process are already available. However, our marine and fisheries institutions are not currently organized to undertake this integration and will have to address ecosystem issues by developing a multidisciplinary scientific approach. This integration, which could be achieved in an incremental way, will substantially improve the perception of ecological research and its usefulness to society. However, it is a task that will compete with other scientific priorities at national levels, as it will require mobilizing efforts. Our society seems to be more interested in, and fascinated with, developing 'telescopes' rather than building 'ecoscopes'. Marine ecosystems sustain our terrestrial life and deserve priority. We need telescopes and microscopes, but we also need ecoscopes. Implementing and operationalizing ecoscopes will crystallize our present scientific knowledge. It requires agreement upon clear and perceivable objectives and adjustment of multiform scientific expertise to societal issues. The potential task is overwhelming, and we need to take pragmatic steps before fully implementing an EAF. Tuning the ecoscope should help us to move towards 'ecosystem ecology' as a discipline in its own right, and towards an effective EAF.

Acknowledgements. Thanks to Dr. Lynne Shannon, who discussed and elaborated with me the ideas that are contained in this essay, and Vera Agostini, Yunne Shin, Andy Bakun, Audrey Colomb, Jean Lefur and Ian Perry for their comments.

\section{Ecosystem-based fisheries management: the carrot or the stick?}

\section{Ray Hilborn}

School of Aquatic and Fishery Sciences, Box 355020, University of Washington, Seattle, Washington 98195, USA Email:rayh@u.washington.edu

In the last few years, a series of papers have been published in high-profile scientific journals describing the role of fishing in the collapse of marine ecosystems
(Jackson et al. 2001, Myers \& Worm 2003), the destruction of marine habitat (Watling \& Norse 1998) and changes in ecosystems that are possible precursors to future collapse (Pauly et al. 1998). The central theme of this 'Litany' is that conventional single species fisheries management has failed and new approaches are needed. A major element of the proposed new approaches is a move from conventional single-species management to 'ecosystem-based management' (NRC 1998). The specific proposed solutions that emerge from the Litany include (1) elimination of subsidies for fishing fleets, (2) reduction of target fishing mortalities, (3) protecting a significant portion (20 to $30 \%$ ) of the world's marine areas from fishing in the form of Marine Protected Areas (MPAs) (Pauly et al. 2002), and (4) elimination of destructive fishing practices (bottom trawling). These approaches require a powerful centralized government and are, therefore, unlikely to be implemented in most of the developing world.

While papers subscribing to the Litany seem to have near exclusive access to the pages of the most prestigious journals, their conclusions are strongly contested within the scientific community. For example, the contention that the predatory fishes of the ocean have declined by $90 \%$ (Myers \& Worm 2003) and, by implication, that these fisheries have collapsed, has been challenged on both the technical nature of the analysis of fishermen's catch records (Walters 2003) and detailed analysis of the fisheries (www.soest.hawaii. edu/PFRP/large_pelagic_predators.html). More simply, the catch data from these fisheries show that they are providing increasing yields, quite contrary to what one would expect from fisheries that Myers \& Worm (2003) classify as having collapsed 20 to 30 years ago.

The contention that MPAs would significantly benefit fisheries yields is equally contested (Norse et al. 2003, Hilborn et al. 2004). Nevertheless, the Litany has dominated public perception of fisheries problems and other authors citing the Litany frequently say that $70 \%$ of the world's fish resources are overexploited or collapsed, rather than fully exploited, overexploited or collapsed. For example, 'According to various official reports, three-quarters of the world's fish stocks have been depleted. Official statistics may well err on the conservative side: overall catches are declining, yet illegal fishing is increasing. The net result is a crisis for natural fisheries.' (O'Riordan 2003). In fact, most of the world's fisheries are not overexploited and continue to be quite productive (FAO 2002a). Within the U.S., only about $16 \%$ of potential yield is being lost due to overfishing (Hilborn et al. 2003).

The scientific objections to the Litany are primarily a matter of degree. No one questions that the majority of the world's fisheries are heavily used, many are overfished, some have collapsed, and good biological and 
economic management suggests substantial reductions in fishing pressure are needed for sustainable management (Hilborn et al. 2003). The major disagreements over possible solutions are not so much where we would like to be, but how to get there. The form of ecosystem management that emerges from the Litany is one that concentrates on the ecosystem in which the fish are embedded and relies on strong central government control. I, and others (Garcia et al. 2003, Sissenwine \& Mace 2003), believe that we need a form of ecosystem management that emphasizes the interaction between fish, fishermen and government regulators and concentrates on incentives and participation with user groups. This difference can be considered as a choice between a participatory approach with incentives as a 'carrot', and a centralized government using regulations as a 'stick'.

The key elements of the current fisheries management approach used in most regulated fisheries in developed countries and international agencies include (1) single species stock assessment to calculate the Maximum Sustainable Yield (MSY) for each stock, (2) a political process to set regulations that determine allowable time, area, gear and catch limits that intertwines allocation between users and conservation, (3) regulation on large spatial scales, (4) a centralized management structure for science, decision making and enforcement with costs paid by governments, and (5) involvement of stakeholders primarily through the political or legal process. It should be noted that most stocks world-wide are not managed in any meaningful way, and any proposals for management, ecosystem or otherwise, need to be achievable. To argue that we need more dataintensive management and more regulation by central governments in the fisheries of the world that have little data and little regulation is untenable.

There have been a wide range of papers dealing with ecosystem management and each of these has a distinct flavor. The 'ecosystem management' I describe here shares elements with the views of others, all of whom emphasize various forms of marine tenure and the dynamics of fishing fleets and regulators. The primary difference between the incentives approach and the forms of ecosystem management emerging from the Litany is governance. The solutions proposed by the Litany rely on strong top-down control to determine objectives and management actions and to assure compliance by fishing industries. The incentives approach recognizes that fisheries are dynamic systems comprised of people and fish (Harris 1998), that top-down control is highly limited in most fisheries, and that good outcomes result from creating incentives that make the interest of the participants in the fishery consistent with the interest of society as a whole. What has failed in conventional fisheries man- agement is not single-species management, but the top-down control as conventionally practiced. In most of the world's fisheries, the commercial and recreational fishermen have significant political power and, hence, attempts to impose regulations that are contrary to their economic interests will most likely fail. Ecosystem management that relies on top-down control for implementation, and makes no allowances for the social/political dynamics of the regulatory structure, is no more likely to succeed than conventional single species management.

What is missing from the conventional single species fisheries management approach is (1) a form of marine tenure-where individuals or groups of fishermen are guaranteed a specific share of future catch - for users that reconciles their economic interest with long-term conservation, eliminates the race-for-fish, and reduces or eliminates incentives for overcapitalization of fishing fleets, (2) recognition that MSY is a poor fisheries management objective and that economic and biological outcomes are better when catches are below MSY and stock sizes consequently higher, (3) direct involvement of stakeholders in data collection, data analysis, and decision making, (4) setting the spatial scale of the data collection, science, and management appropriate to the spatial scales of the fish and the fishermen, and (5) management agencies that explicitly strive for harvesting capacity to match the long-term productive capacity of the resource.

The central theme of this paper is that, by considering humans in ecosystem management, we recognize that appropriate incentives can stop the race-for-fish and eliminate or reduce most of the current problems in fisheries management. In the sections below I explore the nature of incentives, and how incentives interact with other aspects of fisheries management including MSY, institutional structure, and single species management.

Incentives. When there is a race-for-fish, fishermen increase their incomes by fishing harder, building bigger boats and catching fish before someone else does. There is no individual economic incentive for conservation. With various forms of marine tenure, conservation of the resource is in the individual fisher's economic interest. The strongest form of tenure is resource ownership, which is the oldest form of fisheries management in much of the world, found in community control of fishing grounds in the western Pacific (Johannes 2002) and now used as the primary management system in Chilean artisanal fisheries (Castilla \& Fernández 1998). A different form of ownership is allocation of fishing rights by the state through high access fees or auction as is practiced in the Falkland Islands (Barton 2002) and in Washington State for management of geoduck. 
This contrasts with conventional management in which the state gives away the rights to fish and then uses tax revenue to manage the fishery. When high access fees are charged, the state has both the incentive and the revenue to implement stringent top-down control. Tenure granted to cooperatives is another mechanism to stop the race-for-fish since it allows the cooperatives to concentrate on economic maximization of yield from the fishery. Coops have been implemented for hake and pollock on the west coast of the U.S., for salmon in the Chignik area of Alaska, and for several fisheries in Mexico. The most broadly used form of marine tenure is individual quotas in which a specific portion of the total catch is allocated to individuals or vessels. Individual Transferable Quotas (ITQs), under which individuals can catch and/or sell their right to catch a portion of the total allowable catch, have now been implemented in New Zealand, Australia, Iceland and several specific fisheries within the U.S. and Canada. ITQs, like other forms of marine tenure, provide incentives to reduce fishing capacity to a level appropriate for productive capacity of the resource and to concentrate on minimizing costs and maximizing value of the catch, since the total catch is determined by a science-based public process (NRC 1999a).

Single species management. A major element in the Litany is a list of fisheries collapses that includes the sea otter, the great whales, the northern cod, and bluefin tuna (NRC 1999). In fact, none of these really illustrate that single species management cannot work. Rather, they are examples of failures to do single species management properly, since the stocks were generally fished down to less than $1 \%$ of their original biomass - far below single species guidelines of 25 to $50 \%$. Sea otter, great whales and bluefin tuna were largely unregulated and highly valuable. The natural outcome was to move to the bio-economic equilibrium which is near extinction. For these stocks, single species management did not fail, it wasn't practiced. In northern cod, the scientific/political system failed (Harris 1998). While ecosystem changes may have resulted from the severe depletion of these stocks, these changes would likely not have happened had the stocks been maintained at the abundances called for under conventional single species management. Thus, this list of fisheries failures suggests that the problem was poor implementation of single species management rather than a need to move beyond it.

MSY. MSY emerged in the 1950s as the default management objective within fisheries science. However, by the mid-1970s it had been largely discredited among scientists who recognized that maximizing the tons of fish landed was unlikely to be the appropriate goal of fisheries management (Larkin 1977). Yet, be- ginning with the Law of the Sea, and later through national legislation in many countries, MSY became firmly enshrined as the default objective of fisheries management. The result is that management agencies now try to determine the maximum yield that could possibly be obtained from a fish stock, and regulatory agencies try to set catch limits at the maximum that could be harvested. This ignores the fact that the economic optimum is almost always at yields lower than the MSY, and involves less fishing pressure. Once the race-for-fish is eliminated, the fishing industry recognizes that it is better served by higher stock size and, consequently, higher catch-per-hour fished as well as lower, but more stable catches. MSY is often incompatible with economically viable fisheries.

Political decision making and stakeholder involvement. The track record of most fisheries management agencies is not good, and this failure has often been blamed on the participation of self-interested stakeholders in the decision-making process. This has led to frequent calls for 'science based management,' in particular for the elimination of commercial and recreational fishermen from the decision making process. I argue that the major problem with political decision making as commonly practiced is that the allocation between competing groups (nations, gear types, communities) and the questions of conservation and sustainability are not distinguished. As most fisheries involve individuals or groups competing for a share of the fish, the agencies often spend almost all their energy on allocation between competing users. Once the race-for-fish is replaced by some form of tenure, representatives of fishing groups will become an interest group with a high vested interest in making decisions that will allow for the long-term sustained use of the resource. With appropriate incentives, commercial fishing groups have often called for lower catches, have engaged in data collection and analysis, and have often even funded the majority of the scientific advising process.

Ecosystem management of fish and fleets. The important elements in incentive-based ecosystem management are fishing fleets and fish, rather than fish and their ecosystem. The dynamics of investment, fish harvesting, markets, and the incentives for fishermen to conserve fish are, the most important considerations for sustainability. The trophic interactions between species, the dynamics of marine ecosystems, or the scientific approach applied in determining quota recommendations are secondary considerations. Following from this, ecosystem management should have the following characteristics: (1) incentives in the form of marine tenure will be in place so that the long-term economic and social benefits of all participants will be maximized by sustainable fishing practices; (2) data 
collection, analysis, setting regulations, and enforcement, will be on the spatial scale appropriate to the biology of the fish and the structure of the fishing communities; (3) stakeholders will be intensively involved in all levels of science, management and enforcement, and under some circumstances fishing groups will have complete control over the resource; (4) all costs of research, management and enforcement will be paid by user groups; (5) the primary role of central governments will be to audit the system to assure that the biology and economics of the fishery are sustained and to ensure that national/international agreements and laws are respected and enforced; and (6) substantial portions of the marine ecosystem will be protected from fishing activity to provide biodiversity reserves and reference sites (in the sense of an unexploited control group).

The Pew Oceans Commission identified governance structure as the key failing in U.S. fisheries policy (Pew Oceans Commission 2003), and recognized the need to separate allocation from conservation decisions. However, this commission did not see a significant role for incentives. Rather, it recommended strong, centralized, top-down control. The top-down approach contrasts with the incentives approach in that the former often views the exploiters of marine resources as natural destroyers of marine environments who need to be excluded from decision making as much as possible, while the latter views them as necessary partners in achieving good management.

Where economic incentives are not enough. The strict economic incentives associated with marine tenure will not protect all ecosystem components from the effects of fishing. For example the following topics would still need to be addressed: (1) unproductive species in mixed species fisheries; (2) by-catch of threatened or endangered species; (3) trophic impacts of fishing; (4) habitat impacts of fishing; (5) long-lived species where the economic optimum is depletion; and (6) where international jurisdictions makes granting tenure difficult or impossible. The economic return to tenure holders is not increased by avoiding these problems and here I see governmental agencies having an important auditing role. Consider a theoretical example in which some group had been granted ownership and management rights to fishing grounds. The tenure holder should be required to develop a management plan associated with the areas of concern listed above, that would include monitoring, evaluation and enforcement. The management plan might involve mandatory by-catch quotas, gear modifications to avoid non-target species, prohibition of destructive fishing gears, or overall catch quotas on some nontarget species. For many fisheries, this may require intensive, perhaps complete, observer coverage. While this is very expensive, it may well be the true real cost of achieving economically sustainable fisheries that meet society's goal to protect biodiversity. Alternatives might include expanding protected areas as reserves for by-catch species that would then be unprotected in the exploited areas. Incentives have an important role to play because the higher the market value of a specific form of tenure is, the more important it is to the tenure holder not to have the tenure revoked due to violation of regulations.

By offering user groups marine tenure that gives them much more direct control of their own destiny, and of a highly valuable asset, governments have been able to obtain agreements with fishing groups to accept and maintain industry funding of the costs of fisheries research and management (Australia, New Zealand, Iceland, Chile) as well as intrusive and expensive observer coverage. I am not advocating ITQs, and the usual allocation based on catch histories, as the primary form of tenure. There are many other forms of tenure that would achieve the desired goals, among them state ownership with high access fees and cooperatives. However, to achieve a politically viable transition from our current system to a tenure system something has to be offered to the fishermen. The obvious solution is a significant portion of the future catching rights in the form of ITQs, with the remainder owned and leased by the state.

Summary. Ecosystem management means different things to different authors. I present here my vision of the key elements of such an approach. The emphasis on institutions and the evolution of current single species management approaches is consistent with many others, but differs greatly from the 'revolutionary' change called for in response to the perceived failure of single species management. I see the failures of fisheries management as being due to a failure to recognize the importance of people and people management, not due to single species management. I support the view of ecosystem management that recognizes the institutional dynamics between harvesters, managers and scientists, and stops the race-for-fish and overcapitalization through incentives rather than stopping overfishing through centralized top-down control. I share with the papers of the Litany a common vision of the world's fisheries that have smaller fishing fleets, higher stock biomasses and significant areas protected from fishing. However, I see a very different way to achieve these goals. In my vision incentives are key, fishermen are involved in all aspects of management, and they also pay for the annual costs of fisheries management.

Acknowledgements. I thank Doug Butterworth, Serge Garcia, Loo Botsford, Dan Huppert, J. J. Maguire and Kevin Stokes for comments on the manuscript. 


\section{The ecosystem approach to fishery management: a significant step towards sustainable use of the marine environment?}

\author{
Simon Jennings \\ Centre for Environment, Fisheries and Aquaculture Science, \\ Lowestoft Laboratory, NR33 0HT, UK \\ Email: s.jennings@cefas.co.uk
}

Environmental managers regulate human activities to improve ecological, social or economic sustainability. Such regulation is not always effective, and most fisheries are seen as excellent examples of failed natural resource management. While regulation and societal pressure have often led to reductions in the environmental impacts of shipping, aggregate dredging, waste disposal and the oil and gas industries, fishing is widely seen as the remaining pariah, currently attracting the attention of the global media and numerous conservation and lobby groups.

Today, most fisheries are managed on a stock-bystock basis. Reference points are established for stock biomass and fishing mortality and then catch controls, effort controls or technical measures, such as changes in mesh size or area closures, are recommended to managers to modify mortality rates. In reality, managers have always struggled to reduce fishing mortality, and the biomass of many stocks is below intended reference points (FAO 2002a). The failures of management are catalogued in numerous publications and the principal ecological, social and economic reasons for failure are well understood (OECD 1997, FAO 2002b). This understanding has thus far done little to improve the overall effectiveness of management in ecological, social or economic terms.

Although the depletion or collapse of target stocks is often the most visible and well-publicised failure of the fisheries management process, fisheries take place in ecosystems and have wide ranging ecological impacts. These impacts have become an increasing focus of research effort, as evidenced by recent symposia (Gislason \& Sinclair 2000, Kaiser \& de Groot 2000, Sinclair \& Valdimarsson 2003) and reviews (Gislason 1994, Dayton et al. 1995, Jennings \& Polunin 1996, Jennings \& Kaiser 1998, Hall 1999, NRC 2002). This interest in fisheries ecosystem interactions is not new (e.g. Anderson \& Ursin 1977, Pope 1979, Pope et al. 1988) but the recent shift in research effort from single species to ecosystem-based concerns reflects the growing recognition that an ecosystem approach may help to underpin improved management.

From a policy perspective, the move towards an ecosystem approach has been rapid and is consistent with wider commitments to sustainable development. Indeed, while many commentators are still asking for fishing impacts to be considered in environmental policy, the requirements to protect ecosystems from the wider impacts of fishing, and to adopt an ecosystem approach, have already been written into most of the key policy documents relating to marine environmental management (Sainsbury \& Sumaila 2003, Rice 2004). The ecosystem approach, as described in existing policy documents (e.g. WSSD 2002), contributes to sustainable development, which requires that the needs of future generations are not compromised by the actions of people today. The ecosystem approach is variously defined, but principally puts emphasis on a management regime that maintains the health of the ecosystem alongside appropriate human use of the marine environment, for the benefit of current and future generations.

EAF is part of the ecosystem approach. The broad purpose of the EAF is to plan, develop and manage fisheries in a manner that addresses the multiple needs and desires of societies, without jeopardising the options for future generations to benefit from the full range of goods and services (including, of course, non fisheries benefits) provided by marine ecosystems (FAO 2003). The success of an ecosystem approach will depend on whether these high level and somewhat abstract commitments can be turned into specific, tractable and effective management actions (Sainsbury et al. 2000, Sainsbury \& Sumaila 2003).

To assess the potential of the ecosystem approach, we need to ask whether it will nullify the failings of existing approaches and change attitudes to use of the marine environment. From ecological, economic and social perspectives, existing management methods have generally failed. Thus, $47 \%$ of the world's main stocks or species groups are fully exploited, while $18 \%$ are overexploited and $10 \%$ are severely depleted or recovering from depletion. Only $25 \%$ of stocks are under- or moderately exploited (FAO 2002a). The FAO conducted one of the most comprehensive analyses of the factors contributing to unsustainability in fisheries (FAO 2002b). These were inappropriate incentives and market distortions, high demand for limited resources, poverty and lack of alternatives to fishing, complexity and inadequate knowledge, lack of governance, and interactions of the fishery sector with other sectors and the environment (FAO 2002b). Their analyses showed that scientific advice on the status of fish stocks and the effects of fishing made only a small contribution to a complex management and decision-making process, and often carried little weight in relation to immediate social and economic considerations. Advice on fisheries exploitation in an ecosystem context will also make a small contribution to a larger process that is 
influenced by many of the same social and economic factors. Thus, scientific advice may carry little weight when there are very high short-term social and economic costs associated with moving towards sustainability. These costs are common to both single species and ecosystem-based approaches (Rice 2004). The ecosystem approach will not remove the very high short-term costs of protecting the environment unless incentives are introduced to link conservation and short-term financial reward.

From an ecological perspective, the ecosystem approach recognises, and aims to remedy, the unwanted impacts of fishing on non-target species, habitats and ecological interactions. The approach recognises that ecosystems provide goods and services other than fish and may change the burden of proof if existing management is not precautionary (Sainsbury \& Sumaila 2003). However, in the broadest directional terms, scientific advice is consistent from both single-species and ecosystem perspectives: significant capacity reductions are needed. The most pervasive ecosystem impacts are still the result of massive over capacity, and scientific advisers on single-species issues have been arguing for capacity reductions and time or area closures for decades. Managing fisheries in an ecosystem context also leads to advice to reduce capacity and implement time or area closures. True, there are cases where otherwise sustainable fisheries have additional adverse effects on non-target species and habitats (Witherell et al. 2000) but, at the present time, such fisheries are in the minority relative to those where mortality has to be cut simply to ensure conservation of target stocks. Indeed, the ICES Advisory Committee on Ecosystems concluded that managers would have to deal with a much smaller and more tractable set of ecosystem issues if capacity were reduced to the extent that all target stocks were fished sustainably (ICES 2001).

The preceding arguments suggest that the transition from single-species to ecosystem-based approaches will not alter the high short-term social and economic costs of reducing capacity nor the general advice that capacity should be reduced. Thus, scientific advice on the North Sea cod fishery that is framed in an ecosystem context would not be more stringent than the request for a zero catch in 2004 (ICES 2003a). Perhaps a more relevant issue is whether the adoption of the ecosystem approach will encourage society to exert more pressure on Governments to bear high shortterm costs, and to translate high level political commitments into capacity reductions and improvements in the ecological status of the marine environment. Ultimately, society's willingness to bear these high shortterm costs, directly or indirectly, will determine the success or failure of the ecosystem approach. Market instruments that capture at a private level the social and global values of relatively undisturbed ecosystems through, for example, premium pricing for fish caught from healthy ecosystems (Phillips et al. 2003), may help to increase the short-term benefits associated with conservation. However, such instruments will not promote conservation in many areas where unsustainable fisheries provide the main source of food, income and employment. This requires a willingness of Governments to commit substantial international funding, but the gap between commitment and available funding is large and growing (UNDP 2003).

Scientific research has shown that the sea provides essential ecosystem goods and services with high longterm value (Balmford et al. 2002), yet human impacts on the sea are rarely an important political issue in comparison with health, poverty, education and military disputes. Management of the marine environment is not a top spending priority for Governments because it does not have an immediate impact on most voters lives. Public attitudes, rather than new types of scientific advice, are most likely to change this. In this respect, high profile and media friendly conservation projects, such as those supported by the Pew Charitable Trusts, will have a significant role in changing public perceptions, and may serve to increase the shortterm political costs associated with the failure to move towards sustainability.

The extent to which society can strengthen the case for management action was well demonstrated by the effects of consumer and conservation campaigns on attitudes to marine mammal bycatch. Indeed, pressure on the US Government led to the implementation of the Marine Mammal Protection Act in 1972. This required the adoption of fishing practices that reduced dolphin bycatch and the presence of independent observers on vessels to monitor and control bycatches (M. A. Hall 1998). By 1972, another bycatch species, the common skate Dipturus batis, was effectively extinct in the Irish Sea (Brander 1981). There was little public interest in the common skate, and over $30 \mathrm{yr}$ later no specific measures have been implemented to protect this species (Dulvy et al. 2003). Clearly, the influence of society on commitments to policy implementation has the potential to create ecosystems that are dominated by 'favoured' species. Although the ecosystem approach is intended to take account of human impacts on the whole ecosystem, the first steps towards implementation may be remarkably piecemeal and have a range of unexpected consequences.

Thus far, attempts to implement an ecosystem approach have often been characterised by a polarised debate between 'ecosystem' and 'stock assessment' scientists, and the unwillingness of some advocates of ecosystem based management to accept useful parts of 
the existing management system. The most effective progress towards an ecosystem approach is likely to be achieved by moving forward collectively, integrating the useful aspects of existing approaches into new ones. There are 2 reasons for this. First, both ecosystem- and stock-based approaches, at least at a global scale, lead to the same advice; to reduce fishing capacity and restrict access. Second, it has taken a long time to improve understanding of the issues that affect the success of environmental management, such as dealing with risk and uncertainty (Hilborn 1996, Harwood \& Stokes 2003), and such insight should not be wasted. The assumption that solutions are simple, but overlooked or untested, has led to many false dawns in environmental management.

One such concern exists in relation to closed areas, which are increasingly proposed as an almost singular solution to the adverse effects of fishing. While closed areas are an important management tool, and are frequently not used even when they could mitigate unsustainable fishing impacts (Sainsbury \& Sumaila 2003), a single-minded focus on area closure as opposed to capacity reduction and other measures is unlikely to reduce significantly the aggregate impacts of fishing. Thus, increased use of closed areas without associated capacity reduction will displace fishing impacts to places where fisheries regulations are not so stringent, and to more vulnerable areas, such as parts of the deep sea (Koslow et al. 2000). Progress towards effective ecosystem-based management will ultimately depend on both access restriction and effective capacity reduction. However, the increasing application of area closure in supporting aspects of ecosystembased management (e.g. protection of vulnerable habitats, genetic diversity or food web structure) will begin to play an important role in changing perceptions about open access to the marine environment.

The ecosystem approach is sometimes seen as endlessly complicated, and it is a common misconception that we need to understand the structure and function of entire ecosystems to implement effective ecosystembased management. While understanding ecosystems is a worthy intellectual exercise, it can be an inappropriate and unrealistic use of limited resources that could be used to address specific and tractable issues. True, the science required to underpin the ecosystem approach will be more diverse than that contributing to fisheries stock assessment, but funding for this science cannot be expected to increase in proportion to the range of ecosystem issues that scientists will be asked to address. The most significant and cost-effective progress towards the ecosystem approach is most likely to be made by appropriate reorientation of existing science and management tools. An emphasis on an evolutionary rather than revolutionary move towards the ecosystem approach is less likely to paralyse the decision-making process and will help to maintain broad based support.

From a practical perspective, the essential diversity of scientific involvement in the ecosystem approach can readily confuse managers. Thus fisheries managers who once turned to stock assessments, now have to consider genetic and species diversity (Law 2000, Murawski 2000), species rarity (Casey \& Myers 1998, Schindler et al. 2002), habitats (Collie et al. 2000, Kaiser et al. 2002), food web properties (Pauly et al. 1998, Cury et al. 2003) and the ecology of marine mammals and birds (M. A. Hall 1998, Tasker et al. 2000) when managing the marine environment. Fishing has become an issue on which most ecologists have strong opinions, but the breadth of knowledge and experience required to provide balanced and credible advice that can actually be used by decision makers is formidable (Sissenwine \& Mace 2003). It will also be difficult for managers to reconcile the range of advice they receive in the absence of established guidelines on the implementation of an ecosystem approach; though some management agencies have such guidelines (Constable et al. 2000, Witherell et al. 2000) and most others are working towards them (FAO 2003, Rice 2003).

One component of the ecosystem approach that may play an increasing role in shaping the future of marine environmental management is the use of environmental impact assessment. Fisheries are effectively exempt from the requirements for impact assessment, even in areas where other users of the marine environment, such as the oil and gas industries, would be required to conduct them. There is a precedent for a move towards environmental impact assessment in the FAO Code of Conduct for Responsible Fisheries (FAO 1995b), which suggests that conservation and management should be cautious until sufficient data for assessment are available. Impact assessment would usefully deal with social and economic as well as ecological factors, but would need to incorporate an agreed long-term perspective to reduce the significance of high short-term costs. Moreover, the application of impact assessment would require new management structures that facilitated collaboration between marine ecologists, social scientists, lawyers and economists, but did not paralyse the decision-making process.

To conclude, the mechanisms to implement an ecosystem approach are increasingly well developed and such an approach will improve sustainability in wealthier nations, provided that society is strongly supportive. With support from society, management methods would be expected to evolve quite rapidly until fisheries are treated on a par with other sectoral activities that impact the marine environment. It is 
expected that the capacity of fishing fleets will be much reduced, there will be fewer subsidies, new fisheries will only be licensed following impact assessment and habitat and species conservation issues will become an increasing focus of management plans. Indeed, the work of the North Pacific Fishery Management Council suggests that the ecosystem approach can be implemented effectively when there is sufficient commitment (Witherell et al. 2000). In many poorer nations, prospects for improved sustainability are not good, unless the international community commits to supporting and financing the ecosystem approach and subsidising the very high short-term social and economic costs associated with reducing capacity.

Acknowledgements. Many thanks to Colin Bannister, Nick Dulvy, Joe Horwood, Jake Rice and the editors of this TS for helpful comments on the text. Their generosity in reading the text does not necessarily mean that they all agree with my opinions!

\section{Repetitive history of resource depletion and mismanagement: the need for a shift in perspective}

\section{Heike K. Lotze}

Wattenmeerstation Sylt, Alfred Wegener Institute for Polar and Marine Research, Hafenstrasse 43, 25992 List, Germany

Present address: Leibniz Institute for Marine Science, Experimental Ecology, Düsternbrooker Weg 20, 24105 Kiel, Germany Email: hlotze@ifm-geomar.de

History tends to repeat itself. Plentiful resources always impressed humans as being inexhaustible. We exploited them without thinking much about ecological consequences and replenishment. Only when resources declined did we start to implement management actions such as privatization, quotas, closed seasons and other restrictions. High human demand as well as economic, social or political pressures, however, often undermined sufficient management practices leading to overexploitation and collapse. Unfortunately, human societies usually did not question their actions or demands when resources collapsed, but moved on to either (1) exploiting the same species somewhere else, (2) exploiting a less preferred species locally, or (3) intensifying local resource production through aquaculture. Today, these 'solutions' are still widely used, but hardly work anymore. We have reached global limits of exploitation at the poles, the open ocean and the deep sea. We have successively depleted lakes, rivers, coastal seas, and finally the open ocean, leaving many species overexploited, endangered or extinct. Although a potential solution to substitute for depleted stocks, aquaculture of high trophic level species faces limits. Single-species management approaches aiming for maximizing resource output to humans have often failed to prevent depletion and collapse. Multiple human impacts that destroy habitat and environmental quality essential to the sustenance of aquatic species need to be considered. If 'ecosystem-level' management is used just as a new label hiding the continuation of ongoing practices and attitudes, we will drive aquatic resources to further depletions, collapses and extinctions, possibly passing the point where recovery would still be possible. There is an alternative. Ecosystem-level management should aim for managing ecosystems with the goal of optimal functioning of all parts, including ourselves. This requires a shift in perspective. We are faced with the challenging opportunity to break our historical patterns.

Repetitive history of resource use and management. Apparent inexhaustibility of unexploited resources: Whenever people in the past encountered oceanic regions that were formerly not or only little exploited, the vast richness of large fish, birds, turtles, whales, and other marine animals astonished them. Whether people visiting the Baltic or North Sea 1000 yr ago (Hoffmann 2001, 2002), or Europeans reaching the New World 500 yr ago (e.g. Cabot 1497/98 cited in Hoffmann 2001, Rosier 1605 cited in Steneck 1997), their descriptions are similar. The newly discovered seas and the bounty of life always seemed inexhaustible. Even in the 19th and 20th century, people continued to believe in this myth of inexhaustibility (Hutchings \& Myers 1995, Pauly et al. 2003). Throughout our history, we have repeatedly proven ourselves wrong.

Human population density and demand: Prehistoric people hunted, fished and gathered to sustain themselves or to trade with neighbors. Archaeological evidence suggests that in regions with low population density indigenous people had no or little impact on common target species such as marine mammals, birds, fish and shellfish (Steneck 1997, Lotze \& Milewski 2004). In contrast, in regions with high human population density, most valued species declined in relative abundance, size or distribution over time, indicating high exploitation pressure (Broughton 1997, Smith 2004). Thus, in some hunter-gatherer societies human population density and demand was already high enough to cause severe resource depletion.

Since then, human population has grown exponentially and demands have multiplied, not only for food, but increasingly for profit, fashion, and prestige. For example, rare sturgeon or salmon were reserved for kings and the elite in the late Middle Ages (Hoffmann 2001), whales were hunted for their baleens, which were used in ladies' fashion, and seabirds were killed in the millions to supply the millinery trade in the 19th 
century (Lotze \& Milewski 2004). Excessive exploitation has resulted in rapid depletion and extinctions since the Middle Ages, and especially in the 19th century (Hoffmann 2002, Lotze \& Milewski 2004). Fishers, hunters, traders and entire nations increasingly competed in the rush for valued but dwindling resources (Hoffmann 2002).

Shifting values and subsequent conservation efforts in the 20th century led to the recovery of some species (Murawski et al. 2000, Cloern 2001, Lotze \& Milewski 2004). Today, ocean wildlife is exploited to meet the food demands of an ever-increasing human population, as well as to supply global luxury markets. This growing demand, however, is restrained by an increase in the number of collapsed or overexploited fish stocks, and declining global catches (Botsford et al. 1997, Pauly et al. 2002, Myers \& Worm 2003, 2004). While human population growth in the Middle Ages was mainly fuelled by the supply of cereals (Hoffmann 2001), today's population demands a continuous supply of fish and meat. Clearly, as a society, we need to adapt our demands to the capacity of marine ecosystems, not vice versa.

Resource depletion and management: Throughout history, humans have reacted to local resource depletion by implementing management actions that belonged to 4 major categories: (1) privatization and regulation, (2) expansion to unexploited regions, (3) substitution of depleted target species with less exploited species, and (4) intensification of local production through aquaculture.

In the Middle Ages, human population density increased markedly throughout Europe and the first signs of depletion of preferred aquatic food sources such as sturgeon and salmon were already evident in the 13th century (Hoffmann 2001). Privatization and regulation with quotas, gear, seasonal and other restrictions were implemented by landowners or territorial authorities (Hoffmann 2002). However, in the Middle Ages, as well as today, these management practices were often overridden by socio-economic pressures (Botsford et al. 1997). Therefore, a continued decline in resources led to the expansion of frontiers to formerly unexploited regions. Fisheries moved from freshwater to marine environments in medieval Europe (Hoffmann 2001, 2002), from inshore to offshore in the North Sea and North Atlantic beginning in the 1400s (Hutchings \& Myers 1995, Steneck 1997, Hoffmann 2002, Lotze \& Milewski 2004), and to the open ocean, polar and deep seas in the 19th and 20th century (Pauly et al. 2002, 2003, Myers \& Worm 2003). The history of whaling shows a similar pattern of spatial expansion from coastal to offshore and polar regions, as well as serial depletion of one species after another. This successive substitution of depleted target species with formerly unexploited species that were less valued, smaller, harder to catch, or lower in the food web is the third common management practice (Fig. 1). Today, low-trophic level exploitation of crustaceans, mollusks and marine plants dominate most coastal fisheries (Pauly et al. 2002, Lotze \& Milewski 2004). The fourth form of management practice is intensification of local production. Like fishing, aquaculture moved from freshwater to anadromous to marine fishes. Aquaculture of introduced carp was invented in the Middle Ages (Hoffmann 2002), that of salmon in the $1970 \mathrm{~s}$, and today farming of marine groundfish such as cod or haddock is becoming a reality. In contrast to herbivorous carp, however, aquaculture of piscivorous fish faces limits and creates many environmental problems (Pauly et al. 2002).

Whether it is privatization and regulation, expansion, substitution, or intensification, we still repeat historical patterns, albeit on a global scale (Botsford et al. 1997, Pauly et al. 2003). Today, depleted aquatic resources are the rule rather than the exception. Large, long-lived species such as northern right and humpback whale, great auk and Labrador duck, sturgeon and salmon, haddock and cod, sharks and rays are extinct or rare, i.e. at around 1 to $10 \%$ of their former
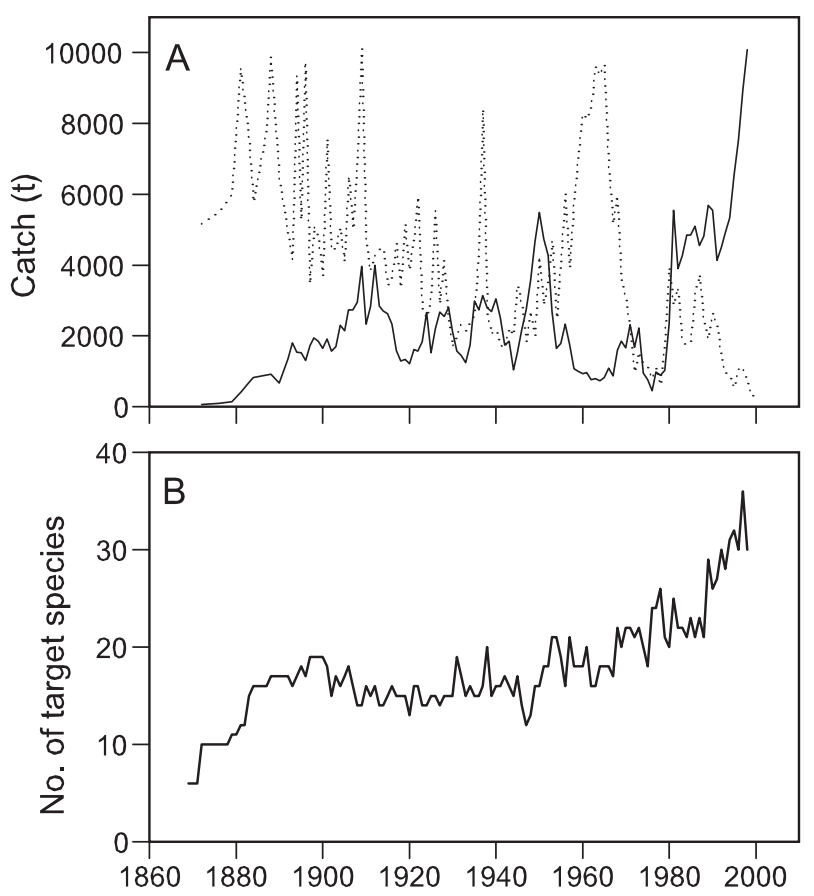

Fig. 1. Substitution of depleted resources in the Outer Bay of Fundy, NW Atlantic. (A) Declining catches of traditional groundfish (cod, haddock, pollock; dotted line) led to increasing invertebrate and plant landings (solid line). Note that high groundfish landings in the 1960s arose from expanding to offshore fishing grounds and the introduction of otter trawls. (B) Increase in the number of target species in commercial fisheries over time. Data adapted from Lotze \& Milewski (2004) 
abundance (Myers \& Worm 2003, 2004, Roman \& Palumbi 2003, Lotze \& Milewski 2004). Traditional management approaches have failed to ensure sustainable use of aquatic resources (Botsford et al. 1997, Pauly et al. 2002), and extrapolation of present trends into the future presents us with a grim picture (Pauly et al. 2003). If aquatic wildlife and ecosystems as well as fisheries productivity is to be sustained, our society needs to shift to more sustainable management and question its demands.

Ecosystem management as a shift in perspective. Towards an ecosystem perspective: For a long time, the goal of single-species management was to manage populations for maximum possible output for humans. If ecosystem-level management is used in the same sense, it will surely only accelerate present patterns of depletion and degradation. Ecosystem-level management should mean that ecosystems are managed with the goal of optimal functioning of all parts including ourselves. This requires that (1) all the parts (species, habitats) are kept, (2) all parts are kept in a state (of abundance, diversity, complexity) that allows longterm persistence and resilience of populations, communities and ecosystems, and (3) high environmental quality is provided to ensure health and survival. It also requires integrating multiple human impacts into an ecosystem framework because humans interfere with all parts through the cumulative effects of exploitation, habitat destruction, nutrient loading, pollution, and other disturbances. Diverse, productive and functioning ecosystems will not only conserve aquatic wildlife and wilderness, but will also likely enhance productivity, water quality, economic options and other goods and services for human societies.

Integrating multiple human impacts: Humans have multiple impacts on aquatic ecosystems that interact with one another and must, therefore, be managed together. Historically, direct exploitation was the first human impact on aquatic resources. In a food web context, humans act as top-predators having 'top-down' impacts which have increased multi-fold from early subsistence cultures to today's societies (Lotze \& Milewski 2004). These direct impacts on populations are complicated by indirect community effects such as depensation and trophic cascades. Moreover, human activities also affect the food web from the 'bottom-up' through resource enhancement such as nutrient loading (Cloern 2001, Lotze \& Milewski 2004). These bottom-up impacts interact with top-down impacts. Reduction of consumers and enhancement of nutrient loads, for example, can result in excessive algal blooms, loss of diversity and ecosystem functions (Worm et al. 2002). Each trophic level is further affected by pollution effects on health, habitat destruction, and increasing stress due to disturbance, traffic and noise. These 'side-in' impacts reduce overall availability of high quality habitat and environment, and the amount of undisturbed space and time (Lotze \& Milewski 2004).

The cumulative effects of top-down, bottom-up and side-in impacts can alter species interactions, accelerate species declines and impair recovery (Lotze \& Milewski 2004). In medieval Europe, deforestation, agricultural expansion, river damming, water pollution, and nutrient loading had already affected freshwater fishes in addition to direct exploitation (Hoffmann 2001, 2002). Recovery of Atlantic salmon was for a long time impaired by river pollution and destruction of spawning habitats (Lotze \& Milewski 2004). Starting in the rivers, multiple human impacts also spread into estuaries and coastal seas, possibly impairing recovery of collapsed groundfish stocks (Lotze \& Milewski 2004). With climate change and worldwide fishing, humans today affect the oceans on a global scale. Former human civilizations collapsed not only because of food shortage but also because of the indirect effects of exploitation such as water and fuel shortage (Hughes 2001). Today, our society has the advantage of knowing what we are doing, and the option of acting upon that knowledge.

Ecosystem-level versus human-impact management: Managing an entire ecosystem will be a difficult task because of our limited understanding of all its parts and the linkages between them. In many cases, however, we have a reasonably good understanding of human impacts and should, therefore, focus on 'human-impact' management in order to reduce our negative and enhance our positive influences. In addition, marine protected areas (no-take zones) are needed as controls to measure change against, as insurance against management failures, to preserve diversity, and to ensure the persistence and resilience of aquatic ecosystems (Palumbi 2001, Worm et al. 2003).

Human-impact management should include technical improvements to minimize negative impacts, protection and restoration of species and habitats, and the reduction of our demand as feasible management options. 'Top-down' impacts can be reduced by effort control through quotas and cutback on subsidies, which will help to re-balance size of fish stocks and fishing fleets (Botsford et al. 1997, Pauly et al. 2002). Protected areas reduce the spatial extent of exploitation and protect threatened diversity (Worm et al. 2003). Technical improvements of more selective and less destructive gear types reduce bycatch and habitat destruction. 'Bottom-up' impacts can be reduced by wastewater treatments at point sources, while restoration of wetlands as natural buffer and filters will reduce non-point pollution (Cloern 2001). Reduction of 'side-in' impacts requires technical improvements to reduce chemical 
pollution, noise stress, and destructive harvesting practices, in addition to protected areas that allow habitat regeneration and species recovery (Murawski et al. 2000, Palumbi 2001). Technical improvement of aquaculture can reduce discharges of chemicals, pharmaceutics, and wastes into the environment.

Reducing excessive and destructive exploitation and enhancing habitat availability and environmental health were successful measures for recovery of some birds, mammals, fish and invertebrates in the 20th century (Murawski et al. 2000, Cloern 2001, Lotze \& Milewski 2004). It is the role of scientists to explore, test, communicate, and insist on implementation of the best management options. It is the role of society to take responsibility for its impacts and act upon the best available knowledge.

Chance and challenge. Throughout history, the ocean was seen as the last frontier, the last wilderness untouched by human activities. This is not true anymore (Bostford et al. 1997, Pauly et al. 2002, Myers \& Worm 2003, 2004), and it hasn't been true for centuries (Hoffmann 2001, 2002, Jackson et al. 2001, Lotze \& Milewski 2004). Exploitation, habitat destruction, pollution, eutrophication, invasions, and climate change have altered the seas rapidly and on a global scale. It should come as a warning, that former civilizations missed the point of return and collapsed because of the unforeseen direct and indirect effects of exploitation and habitat destruction (Hughes 2001). In contrast to them, and indeed for the first time in history, our society is in a position to understand where we are. This is a unique chance and challenge to break our historical patterns. Because of our global impacts, it might be our only one.

Acknowledgements. Many of the ideas expressed in this paper resulted from discussions with Boris Worm. I acknowledge support by the History of Marine Animal Populations (HMAP) program, funded by the Sloan foundation.

\section{In defence of fisheries scientists, single- species models and other scapegoats: confronting the real problems}

\author{
Pamela M. Mace*
}

Ministry of Fisheries, PO Box 1020, Wellington, New Zealand Email: pamela.mace@fish.govt.nz

The current perception of the status of marine species. Articles decrying the negative impacts of overfishing have been written for more than 5 decades, but it is only relatively recently that this has become a

*The views expressed here are those of the author only and do not reflect agency policy or opinion major public issue. The frequency of such publications has increased dramatically in the last decade. While few would dispute the existence and importance of overfishing in many of the world's fisheries, there are numerous arguments about the severity of the situation, its reversibility, the causes and, particularly, the solutions. I believe that the current perception of the status of marine species and ecosystems is overly alarmist; at best unhelpful and at worst destructive. Many scientific papers have exaggerated the severity and apparent hopelessness of the situation, inappropriate scapegoats have been blamed, success stories have largely been ignored, and either overly simplistic 'solutions' (e.g. MPAs, by themselves) or complex, non-operational 'solutions' (e.g. convoluted systems of ecosystem indicators) have frequently been proposed. In particular, single-species approaches have been condemned, and there has been a call to replace them with often ill-defined 'ecosystem approaches'. These are the main themes on which I elaborate here.

The actual situation. World landings of marine species (excluding plants) are currently about 70 to 80 million metric tonnes (t) depending on the statistics used for China, which is believed to have over-reported catches, particularly since the early 1990s (FAO 2002a). Marine aquaculture adds another 10 to 15 million $t$, with the same uncertainty about Chinese statistics. Because of these and other uncertainties, there is considerable debate about recent and projected trends in landings. Marine aquaculture production is certainly increasing, but global landings of wild marine species could be more or less stable, or somewhat declining (FAO 2002a, Watson \& Pauly 2001b). FAO (www.fao.org) projects that landings from marine capture fisheries will be in the range of 80 to 105 million $t$ in 2010. Others (e.g. Pauly et al. 2003) have presented much more pessimistic scenarios. Regarding the current situation, FAO (2002a) estimates that, of the major marine fish stocks or species groups for which information is available, $10 \%$ are depleted or recovering from depletion, another $18 \%$ are overexploited, $47 \%$ are fully exploited, and $25 \%$ are underexploited or moderately exploited, i.e. only $28 \%$ are overexploited or depleted. Globally, the most pressing concerns are the continued overexploitation of many major marine species and the extent of depletion of both target and associated species, together with concomitant effects on community structure and ecosystem function.

Scapegoats. Fisheries scientists, single-species models, and the concept of Maximum Sustainable Yield (MSY) are 3 targets that are commonly, but undeservedly, singled out as being responsible for the current situation.

Fisheries scientists: In a recent news feature in Nature (Schiermeier 2002), the headline claimed that 
'Commercial fisheries worldwide are being driven to collapse. Quinn Schiermeier wonders why fisheries scientists are failing to halt this pillage, and asks what hope is there for the future sustainability of fish stocks.' Admittedly, this strong and inflammatory statement was not reiterated in the text of the paper, and probably represents editorial licence designed to draw attention to the paper. However, the news feature does go on to claim that, 'At best, [fisheries scientists'] models of the dynamics of fish populations produce imprecise estimates of the maximum catches that can be taken without driving a stock to extinction,' ... 'At worst, the models can incorporate misleading data that simply give the wrong answer, causing scientists to help speed fisheries towards collapse,' ... 'Given such failures, some conservation biologists are now arguing that fisheries scientists must abandon their focus on individual stocks and adopt a whole ecosystem perspective.'

In fact, fisheries scientists are usually tasked with estimating optimal fishing mortality rates, not maximum possible rates, and it is rare that stock assessments themselves are so optimistic that they contribute to a fishery collapse. The more common situation is that results produced by assessment scientists are discredited by some segments of the fishing industry if they indicate the need for reductions in fishing mortality, because this generally means reductions in catches and fishing incomes in the short term. What is usually lacking is the political will to implement restrictive management measures (Mace 1997, 2001).

Single-species models: The much reiterated claim that single-species fisheries assessment models have failed and need to be supplanted with ecosystem models distorts the facts. There are actually few examples worldwide of fisheries that have been managed for any substantial period of time (e.g. a decade or more) at fishing mortality levels at or below fisheries scientists' estimates of single-species optimal levels.

Given the record of fisheries management to date, it is difficult to understand the reasoning that leads to the conclusion that ecosystem-based approaches will succeed where single-species approaches have failed. If one of the major failings of single-species management has been the lack of political will to curtail allowable catches, what is the basis for thinking that there will be greater political will to implement probablyeven-more restrictive limits on catches, in addition to other management measures? Conservationists who advocate throwing out single-species models and single-species management 'because they haven't worked' may be defeating the common objective of restoring depleted stocks and ecosystems. Unlike most ecosystem objectives, the goals of single-species management are usually easily understood, straightfor- ward, and operational. Even by itself, successful single-species management is likely to go a long way towards achieving many so-called 'ecosystem objectives' (NRC 1999b, Mace 2001). For example, bringing high fishing mortalities on target stocks under control is also likely to result in reductions in fishing mortality on associated and by-catch species, an overall decrease in fishing fleet capacity and fishing effort, and concomitant reductions in adverse effects on marine habitats.

MSY: MSY has been condemned for various reasons, including the belief that it is not sustainable (which it must be, by definition; otherwise it has been incorrectly estimated). In fact, sustainability by itself is a very weak criterion for judging success. Fisheries on extremely depleted stocks can, and have, been sustained over very long periods of time, resulting in considerable foregone yields and high risks of stock collapse. In order to achieve the maximum sustainable yield, it is also necessary to maintain high stock biomass. MSY (and its proxies) is one of the most readily understood and operational concepts that have been developed by fisheries scientists. Again, the major problem is not that the concept is flawed, but that it has rarely been treated seriously as a fishing target and is therefore routinely exceeded, often substantially. For this reason, and because additional consideration of ecosystem effects of fishing will likely require even more conservative fishing mortalities, the singlespecies fishing mortality associated with MSY ( $\left.\mathrm{F}_{\mathrm{MSY}}\right)$ is now commonly advocated as an upper limit on fishing, rather than a fishing target (United Nations 1995, Mace 2001). At the least, reducing fishing mortalities on target species to or below the single-species $\mathrm{F}_{\mathrm{MSY}}$ will likely be a major step towards restoring depleted species and ecosystems.

The actual situation in perspective. There is no doubt that overfishing exists in many of the world's fisheries and that, where it does exist, it needs to be corrected. There is also no doubt that many major fish stocks are depleted and in need of rebuilding in order to increase sustainable yields and decrease the risk of collapse to the stocks themselves, the ecosystems of which they are a part, and the fisheries that depend on them. It is the rapidity of the declines of marine species that many people find alarming. Although some coastal systems and individual fish stocks have been exploited for centuries, it is only since about 1950 that open ocean fishing and global landings both began to escalate. Compared to most terrestrial species, the time horizon over which most marine species have declined appreciably is relatively short. However, a far more important difference between marine and terrestrial systems is that the magnitude of declines in most marine species pales in comparison to the situation for 
most terrestrial species. Noss et al. (1995) summarize estimates of the extent of decline of hundreds of terrestrial habitats in the United States and the rest of the world, citing dozens of examples where 95 to $99 \%$ of various habitats have been lost over huge areas, but often over centuries rather than decades. Although some authors, such as Myers \& Worm (2003), claim that there have been large-scale reductions of the order of 80 to $90 \%$ for many marine communities, the analyses leading to these conclusions have been disputed by others (Walters 2003, Hilborn 2004 in this TS). Declines of the order of 50 to $70 \%$ are much more common and, although such levels are likely to affect ecosystem structure and function, they are hardly indicative of impending doom, especially since some amount of reduction in biomass is an inevitable consequence of harvesting a species. Down to a limit (usually assumed to be 30 to $50 \%$ of the unexploited level), reductions in biomass result in increases in the productivity of species by shifting the age distribution to younger, faster growing individuals, and possibly by reducing competition for food and space.

The problem of 'shifting baselines' (not looking sufficiently far back into history; Pauly 1995) is much more prevalent in terrestrial systems than marine. A 50\% decline in a population that has already declined by $99 \%$ from its pre-exploitation level is likely to be far more serious in terms of risk of extinction than a $50 \%$ decline from a more or less unexploited state. Even so, IUCN (2001) and others advocate evaluating declines only over the past 10 years or 3 generations (whichever is longer). While the suddenness and rapidity of declines may be important, longer historical perspectives must also be considered.

In addition, although declines substantially greater than $50 \%$ of the unexploited level probably require correction, they often only tell part of the story for commercially exploited marine species. For example, there has recently been considerable concern about the extent of decline of the spiny dogfish Squalus acanthias off the Atlantic coasts of the United States and Canada (to the extent that some U.S. environmental NGOs have proposed that it be listed on the Appendices of the Convention for the International Trade in Endangered Species of Fauna and Flora). According to the most recent stock assessment (NOAA 2003b), the biomass of mature females declined by about $78 \%$ from $270000 \mathrm{t}$ in 1991 to $58000 \mathrm{t}$ in 2002 . However, the number of individuals comprising the mature female biomass in 2002 was about 22 million. Similarly, the exploitable biomass (both sexes) in 2002 comprised about 63 million individuals, while the total biomass comprised about 224 million individuals (P. Rago, NOAA, pers. comm.). Thus, although there may have been large percentage declines, the absolute numbers remaining are probably still well above levels at which risk of extinction is likely to become a concern.

None of the above is meant to justify or dismiss high levels of depletion of marine species. Rather, the intent is to inject a note of optimism into the current, mostly pessimistic, debate. While few wild terrestrial species can still be exploited sustainably, the situation for marine species is much more positive. And, despite assertions to the contrary, there is strong evidence that it is not too late to reverse recent trends.

Effects of reducing single-species fishing mortalities. One of the most destructive aspects of the alarmists' portrayal of the current state of marine fisheries is the perception that marine systems are heading towards inevitable collapse, if not extinctions on a massive scale, and that it may be too late to do much about it. For example, Hutchings (2000) claimed that 'there is very little evidence for rapid recovery from prolonged declines, in contrast to the perception that marine fishes are highly resilient to large population reductions', and that most marine fish stocks 'have experienced little, if any, recovery as much as 15 years after 45 to $99 \%$ reductions in reproductive biomass'. There are at least 3 major problems associated with the analyses in Hutchings' paper that may undermine his conclusions. First, Hutchings defined a depletion phase as the largest $15 \mathrm{yr}$ percentage decline in mature fish biomass experienced by each of the stocks included in his analysis, without regard for the extent of depletion at the starting point of each time series. Second, he then interpreted subsequent 5, 10 and $15 \mathrm{yr}$ periods as potential recovery periods, without regard to whether or not there was any attempt to rebuild the resources by reducing fishing mortalities. Third, the time series in the database used for his analyses have not been updated since the early 1990s and therefore do not capture the successes of that decade and beyond.

In the last 10 to $15 \mathrm{yr}$, there have been several concerted and successful efforts to bring fishing mortalities under control. These have provided ample evidence that reductions in fishing mortality can lead to recovery of depleted marine resources (Table 2). One of the most dramatic examples is Georges Bank scallops, for which fishing mortality has been reduced from a peak of about 1.74 in 1991 to an historic low of 0.09 in 2002, and biomass has responded by increasing more than 23-fold over the same time period (D. Hart, NOAA, pers. comm.). Similar, but less spectacular, results have been observed on Georges Bank for haddock, yellowtail flounder, and winter flounder (Table 2). Even the local barndoor skate, a species declared by Casey \& Myers (1998) to be 'close to extinction', is now estimated to number several million individuals (K. Sosebee, NOAA, pers. comm.). 
As an aside, it is interesting to briefly examine the role of MPAs in the Georges Bank scallops success story. Although some authors (e.g. Gell \& Roberts 2003) have used Georges Bank scallops as an example of the successful application of marine reserves (no fishing areas), this is only a part of the story. The $17000 \mathrm{~km}^{2}$ of areas closed to groundfish and scallop fishing on Georges Bank in late 1994 (covering about 50\% of the productive area for scallops and $30 \%$ for groundfish) was only 1 component, albeit a very important component, of the suite of management measures that has led to observed reductions in fishing mortality and subsequent increases in total biomass. For Georges Bank scallops, other management measures have included imposition of limited entry, a $41 \%$ reduction in allowable fishing days, an average of about a $40 \%$ reduction in vessel crew size (which substantially limits the amount of product that can be caught and processed each day), and new gear regulations to reduce catches of small scallops (D. Hart, NOAA, pers. comm.). So far, the spillover benefits often attributed to marine reserves (e.g. increased landings) have not been realized. The combined effect of the new management measures has been to reduce total landings from an average of $7472 \mathrm{t}$ for the $5 \mathrm{yr}$ prior to the imposition of the new management measures to $5006 \mathrm{t}$ over the most recent

Table 2. Fish and invertebrate stocks that have exhibited substantial increases in biomass (B) following substantial reductions in fishing mortality (F). In a few cases, a survey biomass catch rate, B(index), is used as a proxy for stock biomass (units $=\mathrm{kg}$ per survey tow) and an exploitation rate index (E) is used as a proxy for $\mathrm{F}$ (units $=\mathrm{kg}$ of catch / $\mathrm{kg}$ per survey tow). Index results should be treated as highly uncertain as they have not been filtered through a stock assessment model. SSB is spawning stock biomass. Units of B or SSB are tonnes unless otherwise indicated. In 2 cases, absolute numbers (N) are used as a proxy for biomass. For all variables (F, E, B, SSB, and N), the first set of subscripts represents the ages over which the values are averaged, and the second set of subscripts represents the years over which the values are averaged. When the values are based on the fully recruited biomass (i.e. that portion of the total biomass that is vulnerable to the fishery) or the spawning stock biomass, the first set of subscripts is omitted. The convention adopted for choosing the years over which to average was to use single year estimates if the values were monotonically increasing or decreasing, but to average over several relevant years if the values were fluctuating without trend around high or low points

\begin{tabular}{|c|c|c|c|}
\hline \multirow{2}{*}{$\begin{array}{l}\text { Common name/ } \\
\text { Species name }\end{array}$} & \multicolumn{3}{|c|}{ Fishing mortality $(\mathrm{F})$} \\
\hline & Maximum & Recent & Magnitude of reduction \\
\hline Georges Bank scallops Placopecten magellanicus & $\mathrm{F}_{91}=1.74$ & $\mathrm{~F}_{03}=0.09$ & 19.3 \\
\hline U.S. mid-Atlantic scallops P. magellanicus & $\mathrm{F}_{92}=1.58$ & $\mathrm{~F}_{03}=0.48$ & 3.3 \\
\hline Georges Bank cod Gadus morhua & $\mathrm{F}_{4-8,94}=1.49$ & $\mathrm{~F}_{4-8,00-01}=0.37$ & 4.0 \\
\hline Gulf of Maine cod G. morhua & $\mathrm{F}_{4-5,94}=2.04$ & $\mathrm{~F}_{4-5,01}=0.47$ & 4.3 \\
\hline Georges Bank haddock Melanogrammus aeglefinus & $\mathrm{F}_{4-7,80-93}=0.37$ & $\mathrm{~F}_{4-7,95-01}=0.16$ & 2.3 \\
\hline Gulf of Maine haddock $M$. aeglefinus & $E_{90-93}=0.98$ & $\mathrm{E}_{00-01}=0.11$ & 8.9 \\
\hline Georges Bank yellowtail flounder Limanda ferruginea & $\mathrm{F}_{4-5,94}=2.56$ & $\mathrm{~F}_{4-5,01}=0.13$ & 19.7 \\
\hline Gulf of Maine yellowtail flounder L. ferruginea & $\mathrm{F}_{3-4,88}=1.40$ & $\mathrm{~F}_{3-4,99-01}=0.63$ & 2.2 \\
\hline Georges Bank winter flounder Pseudopleuronectes americanus & $\mathrm{F}_{93}=0.71$ & $\mathrm{~F}_{99-01}=0.20$ & 3.6 \\
\hline Gulf of Maine winter flounder $P$. americanus & $\mathrm{F}_{5-6,95}=1.85$ & $\mathrm{~F}_{5-6,99-01}=0.11$ & 16.8 \\
\hline Mid-Atlantic winter flounder P. americanus & $\mathrm{F}_{4-5,97}=1.23$ & $\mathrm{~F}_{4-5,01}=0.51$ & 2.4 \\
\hline U.S. Atlantic witch flounder Glyptocephalus cynoglossus & $\mathrm{F}_{7-9,96}=0.96$ & $\mathrm{~F}_{7-9,99-01}=0.40$ & 2.4 \\
\hline $\begin{array}{l}\text { Gulf of Maine / Georges Bank windowpane flounder } \\
\text { Scophthalmus aquosus }\end{array}$ & $E_{90-93}=5.92$ & $E_{99-01}=0.10$ & 59.2 \\
\hline U.S. Atlantic Acadian redfish Sebastes fasciatus & $E_{81-85}=1.19$ & $\mathrm{E}_{00-01}=0.013$ & 91.5 \\
\hline U.S. Atlantic silver hake Merluccius bilinearis & $\mathrm{E}_{63-72}=11.56$ & $\mathrm{E}_{89-99}=0.42$ & 27.5 \\
\hline U.S. Atlantic summer flounder Paralichthys dentatus & $\mathrm{F}_{3-5,83}=2.15$ & $\mathrm{~F}_{3-5,02}=0.23$ & 9.3 \\
\hline U.S. Atlantic striped bass Morone saxatilis & $\mathrm{F}_{1+, 75-80}>0.5$ & $\mathrm{~F}_{1+, 87-01}=0.16$ & $>3.1$ \\
\hline Georges Bank / Gulf of Maine herring Clupea harengus & $\mathrm{F}_{61-75}>0.5$ & $F_{97}=0.05$ & $>10.0$ \\
\hline U.S. Gulf of Mexico king mackerel Scomberomorus cavalla & $\mathrm{F}_{0-11,81-85}=0.19$ & $\mathrm{~F}_{0-11,97-01}=0.15$ & 1.3 \\
\hline U.S. Atlantic sandbar shark Carcharhinus plumbeus & $\mathrm{F}_{88-94}=0.18$ & $\mathrm{~F}_{99-01}=0.082$ & 2.2 \\
\hline U.S. Atlantic blacktip shark Carcharhinus limbatus & $\mathrm{F}_{88-94}=0.064$ & $\mathrm{~F}_{99-01}=0.031$ & 2.1 \\
\hline California sardine Sardinops sagax & $\mathrm{F}_{46-65}=0.88$ & $\mathrm{~F}_{83-02}=0.13$ & 6.8 \\
\hline New Zealand Area 2 snapper Pagrus auratus & $\mathrm{F}_{80}=0.69$ & $\mathrm{~F}_{98-00}=0.17$ & 4.1 \\
\hline New Zealand Area 7 snapper $P$. auratus & $\mathrm{F}_{78-81}=0.26$ & $\mathrm{~F}_{98-00}=0.0088$ & 29.5 \\
\hline North Atlantic swordfish Xiphias gladius & $\mathrm{F}_{1+, 95}=0.56$ & $\mathrm{~F}_{1+, 00}=0.31$ & 1.8 \\
\hline North Sea saithe Pollachius virens & $\mathrm{F}_{3-6,86}=0.83$ & $\mathrm{~F}_{3-6,02}=0.21$ & 4.0 \\
\hline North Sea herring Clupea harengus & $\mathrm{F}_{2-6,73-76}=1.27$ & $\mathrm{~F}_{2-6,78-02}=0.44$ & 2.9 \\
\hline Irish Sea herring $C$. harengus & $\mathrm{F}_{2-6,74-80}=0.92$ & $\mathrm{~F}_{2-6,84-02}=0.37$ & 2.5 \\
\hline Norwegian spring herring $C$. harengus & $\mathrm{F}_{5-14,67-72}=1.65$ & $\mathrm{~F}_{5-14,88-02}=0.12$ & 13.8 \\
\hline Icelandic summer herring C. harengus & $\mathrm{F}_{5-15,64-71}=1.11$ & $\mathrm{~F}_{5-15,81-02}=0.25$ & 4.4 \\
\hline South African sardine Sardinops sagax & $\mathrm{F}_{0+, \text { mid-60s }}>0.35$ & $\mathrm{~F}_{0+, 90-02}=0.064$ & $>5.5$ \\
\hline
\end{tabular}


5 yr. In fact, recent landings would have been even lower if not for temporary re-openings of the 'closed' areas during 1999-2001. The extent to which the dramatic increase in scallop biomass is the result of the establishment of MPAs per se, or to the contribution of the MPAs to observed reductions in fishing mortality, warrants further analysis. However, it should be noted that mid-Atlantic scallops have also experienced substantial increases in biomass, concurrent with substantial reductions in fishing mortality (Table 2), without the benefit of permanent closed areas.

Other examples of partial or complete recoveries of marine fish and invertebrate stocks for which fishing mortality has been substantially reduced are provided in Table 2, together with estimates of the extent of reduction in fishing mortality and the extent of recovery in biomass. Although this is not an exhaustive list (e.g. Caddy \& Agnew 2003 provide several additional examples), the sum total of all success stories of this nature represents only the tip of the iceberg in terms of the number of stocks that need to be restored globally. As Table 2 demonstrates, single species biomass levels can be rebuilt as a result of concerted efforts to reduce fishing mortality; the problem is that, to date, there have been insufficient concerted efforts to reduce single-species fishing mortalities. When it has not been possible to bring fishing mortality under control, stocks have generally continued to decline or have remained depleted. Unfortunately, there are also several examples (a much smaller number) of stocks that have not recovered following substantial reductions in fishing mortality. An oft-cited example is Northern cod, which has failed to rebuild despite a moratorium on fishing that began in 1992, with only limited subsequent re-openings. Although Northern cod is an important counter to the examples provided in Table 2, it should not be portrayed as the norm.

The real problems. There are 4 major problem areas that need to be addressed to ensure robust and productive marine fisheries and ecosystems for now and the future. These apply regardless of whether singlespecies or ecosystem-based approaches are employed.

Table 2 (continued)

\begin{tabular}{|c|c|c|c|}
\hline Mimimum & $\begin{array}{l}\text { Biomass (B) - } \\
\text { Recent }\end{array}$ & Magnitude of increase & Source \\
\hline $\mathrm{B}_{93}=4500$ & $\mathrm{~B}_{01-03}=105200$ & 23.4 & D. Hart, NOAA, pers comm. \\
\hline $\mathrm{B}_{90-97}=3900$ & $\mathrm{~B}_{00-03}=66700$ & 17.1 & D. Hart, NOAA, pers. comm. \\
\hline $\mathrm{SSB}_{95}=17400$ & $\mathrm{SSB}_{01}=29200$ & 1.7 & NOAA (2002) \\
\hline $\mathrm{SSB}_{98}=10600$ & $\mathrm{SSB}_{01}=22000$ & 2.1 & NOAA (2002) \\
\hline $\mathrm{SSB}_{93}=11300$ & $\mathrm{SSB}_{01}=74400$ & 6.6 & NOAA (2002) \\
\hline $\mathrm{B}(\text { index })_{90-93}=0.28$ & $\mathrm{~B}(\text { index })_{00-01}=13.01$ & 46.5 & NOAA (2002) \\
\hline $\mathrm{SSB}_{95}=2300$ & $\mathrm{SSB}_{01}=38900$ & 16.9 & NOAA (2002) \\
\hline $\mathrm{SSB}_{01}=1600$ & $\mathrm{SSB}_{97}=3200$ & 2.0 & NOAA (2003a) \\
\hline $\mathrm{B}_{93}=2400$ & $\mathrm{~B}_{01}=9800$ & 4.1 & NOAA (2002) \\
\hline $\mathrm{SSB}_{95}=700$ & $\mathrm{SSB}_{01}=5900$ & 8.4 & NOAA (2003a) \\
\hline $\mathrm{SSB}_{94}=2700$ & $\mathrm{SSB}_{01}=7600$ & 2.8 & NOAA (2003a) \\
\hline $\mathrm{SSB}_{95}=4000$ & $\mathrm{SSB}_{01}=11400$ & 2.9 & NOAA (2002) \\
\hline $\mathrm{B}(\text { index })_{91}=0.17$ & $\mathrm{~B}(\text { index })_{01}=0.92$ & 5.4 & NOAA (2002) \\
\hline $\mathrm{B}(\text { index })_{82-85}=4.3$ & $\mathrm{~B}(\text { index })_{00-01}=27.2$ & 6.3 & NOAA (2002) \\
\hline $\mathrm{B}(\text { index })_{64-71}=3.42$ & $\mathrm{~B}(\text { index })_{98-99}=16.80$ & 4.9 & NOAA (2001); L. Jacobson, NOAA, pers. comm. \\
\hline $\mathrm{SSB}_{89}=5200$ & $\mathrm{SSB}_{02}=42200$ & 8.1 & Terceiro (2003) \\
\hline $\mathrm{B}_{1+, 82-83}=6880$ & $\mathrm{~B}_{1+, 99-01}=103700$ & 15.1 & G. Shepherd, NOAA, pers. comm. \\
\hline $\mathrm{B}_{\text {mid } 70 \mathrm{~s}}<100000$ & $\mathrm{~B}_{97}=2900000$ & $>29.0$ & Overholtz (2000) \\
\hline $\mathrm{B}_{0-11,85}=21600$ & $\mathrm{~B}_{0-11,01}=36000$ & 1.7 & M. Ortiz, NOAA, pers. comm. \\
\hline $\mathrm{N}_{95}=1282200$ & $\mathrm{~N}_{01}=1466000$ & 1.1 & Cortés et al. (2002); E. Cortés, NOAA, pers. comm. \\
\hline $\mathrm{N}_{95}=7899700$ & $\mathrm{~N}_{01}=8204100$ & 1.0 & Cortés et al. (2002); E. Cortés, NOAA, pers. comm. \\
\hline $\mathrm{B}_{1+, 83}=5100$ & $\mathrm{~B}_{1+, 99-02}=980400$ & 192.2 & MacCall (1979); Conser et al. (2002) \\
\hline $\mathrm{SSB}_{81}=1200$ & $\mathrm{SSB}_{01}=4000$ & 3.3 & Gilbert \& Phillips (2003) \\
\hline $\mathrm{SSB}_{80}=5500$ & $\mathrm{SSB}_{01}=22800$ & 4.1 & Gilbert \& Phillips (2003) \\
\hline $\mathrm{B}_{1+, 96}=34200$ & $\mathrm{~B}_{1+, 00}=49700$ & 1.5 & ICCAT (2003) \\
\hline $\mathrm{SSB}_{91}=92800$ & $\mathrm{SSB}_{03}=364000$ & 3.9 & $\operatorname{ICES}(2003)$ \\
\hline $\mathrm{SSB}_{77}=48100$ & $\mathrm{SSB}_{03}=2231000$ & 46.4 & ICES (2003) \\
\hline $\mathrm{SSB}_{80}=5700$ & $\mathrm{SSB}_{99-03}=12100$ & 2.1 & ICES (2003) \\
\hline $\mathrm{SSB}_{72}=313000$ & $\mathrm{SSB}_{95-03}=5896200$ & 18.8 & ICES (2003) \\
\hline $\mathrm{SSB}_{68-72}<20000$ & $\mathrm{SSB}_{03}=526200$ & $>26.3$ & ICES (2003) \\
\hline $\mathrm{SSB}_{84}=42200$ & $\mathrm{SSB}_{02-03}=3690600$ & 87.5 & Cunningham \& Butterworth (2004) \\
\hline
\end{tabular}


(1) Excessive fishing mortality rates: Fishing mortality rates in excess of 2 to 3 times the single-species optimum have been common in the past (Table 2, Mace 2001, NOAA 2002, ICES 2003b), and still exist in many fisheries.

(2) Overcapacity: The problems associated with overcapacity extend well beyond those related directly to economic efficiency and financial viability of fishing fleets. Although in theory overcapacity need have no implication for resource conservation provided that a total allowable catch (TAC) or similar constraint is set and enforced appropriately, in reality overcapacity can seriously compromise fisheries management and enforcement, and may ultimately compromise the validity of stock assessments. Participants in fisheries that are barely financially viable are more likely to: put pressure on fisheries managers to choose TACs from the upper range of confidence intervals or risk analyses; challenge the validity of the science; underreport landings; have higher discard rates in order to maximize the value of landings; cause higher mortality of discards due to lack of time available for careful handling of discards; cause higher cryptic mortality by using unnecessarily large amounts of fishing gear; cause greater amounts of ghost fishing from lost or abandoned fishing gear; and cause more damage to marine habitats by deploying more fishing effort than necessary (Mace 2001). Various authors (e.g. Garcia \& Newton 1996, Mace 1997) have estimated the current global fishing capacity at $1 \frac{1}{2}$ to 2 times the optimum, based on single-species considerations alone. At a minimum, fishing capacity needs to be reduced to levels commensurate with the productivity of the resources being exploited.

(3) Lack of adequate basic data: Lack of knowledge about marine systems is one of the major obstacles to effective decision-making. Even though the precautionary approach (FAO 1995b) dictates that greater uncertainty should be addressed by exercising greater caution, in reality it would be very difficult for fisheries managers to claim something like, 'we know absolutely nothing about the effect of current catches on the biomass of this species; therefore, we are going to slash the quota'. The single most valuable tool for assessing the status of individual stocks, biological communities, and habitats has proven to be consistent time series of data on catches, relative abundance, size distributions, and other biological and physical information. Unfortunately, few such time series exist. In particular, long-term, fishery-independent data have only been collected in a few scattered instances, primarily in developed countries. Without these data, we run the risk of severely depleting or totally eliminating species, without even being aware of it until it is too late. Lack of adequate data is more problematic than lack of adequate models, be they single-species or ecosystem level.

(4) Lack of adequate governance systems: Here, governance is interpreted in the broad sense to include formal and informal rules adopted by the fishing industry, fisheries scientists, and the public, in addition to the rules used for fisheries management (Sissenwine \& Mace 2003). Codes of practice need to be formally or informally developed and adhered to by all relevant players. Fishermen need to implement responsible fishing practices, fisheries managers need to implement responsible fisheries management, fisheries scientists need to produce responsive and credible scientific advice, the public needs to get more involved in the fisheries management process and to better appreciate the level of information required to achieve an appropriate balance between exploitation and conservation, and politicians need to have the political will to create effective legislation and live by it (Sissenwine \& Mace 2003).

Progress. In the last 10 to $15 \mathrm{yr}$, programs to reduce fishing mortality rates have intensified and some are resulting in recovery of depleted fish stocks (Table 2). A few of these successes have been accomplished despite the existence of substantial fleet overcapacity. However, experience has demonstrated that the most effective method for bringing fishing mortality under control is to eliminate overcapacity. In turn, the most effective method for bringing fishing capacity under control is to develop and implement appropriate rights-based systems, i.e. to implement effective governance. These rights have taken a number of forms ranging from Individual Transferable Quotas (ITQs) to community-based co-management. With such rights, participants should have a greater incentive to conserve the fishery resource for the future. Examples of successful reductions in fishing capacity following introduction of rights-based management include New Zealand's inshore fisheries, and various fisheries in Australia, the United States, Canada, Iceland and Chile. Two cases where substantial reductions in fishing capacity have occurred in the absence of rightsbased management are the former Soviet Union, which no longer had the resources to maintain its aging distant water fleet following dissolution, and Japan, which has actively reduced the size of its distant water fleet in recent years.

The prognosis for further reducing fishing mortality rates, eliminating overcapacity and improving governance has also improved appreciably with the recent escalation of international instruments such as the 1993 Convention on Biological Diversity, the 1993 Agreement to Promote Compliance with International Conservation and Management Measures by Fishing Vessels on the High Seas, the 1995 Straddling Stocks 
Agreement (United Nations 1995), and several FAO International Plans of Action including the 1999 International Plan of Action for the Management of Fishing Capacity and the 2001 International Plan of Action for Illegal, Unreported and Unregulated Fishing. Even non-binding agreements such as the FAO International Code of Conduct for Responsible Fisheries (FAO 1995a) are gradually changing the mind-set of fishing nations towards more responsible fishing practices.

The lack of adequate monitoring of marine species, habitats and oceanographic factors is perhaps the most difficult problem of all to address, primarily because of the prohibitive costs associated with conducting surveys of marine resources and the high costs of simply monitoring catches in many countries. Realistic cost-benefit analyses may well indicate that the costs of comprehensive scientific research far exceed both short- and longterm potential economic benefits to the fishing industry. As a result, while a few countries may be improving their monitoring capabilities (e.g. the United States), others are losing funds for research and monitoring. Recent progress includes several ambitious programs under the auspices of the Global Ocean Observing System (GOOS), Global Ocean Ecosystem Dynamic Programs (GLOBEC), and the Census of Marine Life (CML).

Concluding remarks. Holistic, ecosystem-based approaches are obviously required to manage marine resources. However, marine ecosystems are complex and poorly understood, and the most pressing problems are similar regardless of whether one considers individual species or whole systems. We need to develop ecosystem-based approaches to fisheries that build upon and integrate 'traditional' single-species objectives, not solutions that abandon traditional approaches that have never been fully implemented, in favor of what are often ill-defined concepts that may do little to solve the overall problems and may not be operational. Therefore, I advocate ecosystem-based approaches with single-species models and operational single-species objectives embedded as an important component. We need to work on bringing fishing mortality under control, eliminating overcapacity, collecting more and better data, and improving governance systems, at the same time as we explore the utility of so-called ecosystem-based approaches such as MPAs which, by themselves, may or may not result in the restoration of depleted fish stocks and ecosystems (see Sissenwine \& Murawski 2004 in this TS). As Hilborn (2004 in this TS) and Jennings (2004 in this TS) assert, the emphasis should be on evolution, not revolution.

Acknowledgements. This paper has benefited immensely from comments on earlier drafts received from Doug Butterworth, Kevern Cochrane and, in particular, the editors of this TS, Howard Browman and Kostas Stergiou. I would also like to thank those who responded at short notice to my requests for stock assessment information, including Enric Cortés, Carryn Cunningham, Dave Gilbert, Dvora Hart, Larry Jacobson, Ram Myers, Mauricio Ortiz, Paul Rago, Gary Shepherd, Kathy Sosebee and Mark Terceiro.

\section{Moving beyond 'intelligent tinkering': advancing an Ecosystem Approach to Fisheries}

\author{
Michael Sissenwine ${ }^{1}$, Steven Murawski ${ }^{2}$ \\ ${ }^{1}$ NOAA-Fisheries, 1315 East-West Highway, Silver Spring, \\ Maryland 20910-3282, USA \\ Email: michael.sissenwine@noaa.gov \\ ${ }^{2}$ NOAA-Fisheries, Woods Hole, Massachusetts, 02543, USA \\ Email: steve.murawski@noaa.gov
}

In his classic 1953 essay, Round River, the American conservationist Aldo Leopold illustrated the challenge of expanding concepts of living resource management to include consideration of non-target species and ecosystem-level linkages:

If the biota, in the course of aeons, has built some-
thing we like but do not understand, then who but a
fool would discard seemingly useless parts? To keep
every cog and wheel is the first precaution of intelli-
gent tinkering.
(Leopold 1966)

In this quote, Leopold introduces both the concepts of uncertainty in how ecosystems are organized, and the use of precaution in the face of uncertainty. Since Leopold penned his essay $50 \mathrm{yr}$ ago, marine fisheries have relied heavily on single-species assessments of population size and harvest rate to evaluate resource status as a basis for advising management (e.g. Mace 1994, Gabriel \& Mace 1999, Mace 2001). This approach focuses on the most visible 'cogs and wheels' of Leopold. Many have condemned these traditional single-species paradigms, given the current state of the world's living marine resources (FAO 2002a). However, most cases of resource failure have resulted from inadequate institutional controls and not from biological targets that were incorrectly or overoptimistically determined (Sissenwine \& Mace 2003, Hilborn 2004 in this TS).

Species of economic, or other intrinsic value to society, are embedded within complex ecosystems. Over the past $30 \mathrm{yr}$, fisheries science and management have increasingly recognized these interactions and accommodations for them have been added to management programsthough not necessarily under an ecosystem appellation. Today, it is common for fisheries management to address a wide array of factors in addition to single species stock dynamics. As early as the 1970s, the International Convention for the Northwest Atlantic Fisheries (ICNAF) instituted a 'second-tier' quota to at least symbolically take 
account of species interactions, and similarly there has been a cap on the multispecies catch of Bering Sea groundfish since the 1980s. There are numerous examples of regulations to reduce bycatch (particularly for birds, turtles and mammals) and destructive fishing practices. Although less common, there are also examples of trophic interactions and climate variability being explicitly taken into account in fisheries management. With respect to uncertainty, the precautionary approach has been operationalized in many cases, with prudent reference points established to guide management. However, efforts to advance beyond a single-species approach have generally emerged in a piecemeal manner in response to challenges to the legitimacy of fishing. Some regions of the world are advancing much more rapidly than others. Worldwide, it is fair to say that fisheries management is becoming increasingly intelligent in the way it tinkers with ecosystems, although there are polarized views on how rapidly progress is being made.

In this essay we consider (1) requirements for advancing ecosystem-based approaches beyond the intelligent tinkering stage and (2) the roles of marine protected areas.

What is an Ecosystem Approach to Fisheries (EAF)? We believe that an EAF is one that is geographically specified, adaptive, takes account of ecosystem knowledge and uncertainties, considers multiple external influences, and strives to balance diverse societal objectives. ${ }^{1}$ Implementation will need to be incremental and collaborative. The term 'Ecosystem-Based Fisheries Management (EBFM)' is often used, but recently, the FAO concluded that it was better to use an 'Ecosystem Approach to Fisheries - EAF' (FAO 2003, Garcia et al. 2003). The latter terminology conveys an important point. What we are discussing is an approach or process that explicitly takes account of ecosystem processes in the formulation of management measures. The actual management actions that emerge may or may not be qualitatively different from traditional management actions (e.g. a total allowable catch may still be the primary conservation tool), but they are likely to be quantitatively different as a result of taking account of more factors.

Evolving management approaches to incorporate ecosystem-related issues requires extending the mandates of existing management institutions. These institutions must thus address broader societal objectives than previously, and be responsive to a broader community of stakeholders. Such an approach focuses effort on understanding the effects of biotic and abiotic interactions on some subset of species, and second, limits the scope of management related activities to those things likely to have a meaningful impact on

${ }^{1}$ This definition of an Ecosystem Approach has been adopted by our Agency the species or processes of interest. Even with this simplification, the issues remain daunting.

How should ecosystems be delineated? To apply an ecosystem approach, it is necessary to delineate ecosystems. The scale of these ecosystems should be based on the spatial extent of the system dynamics that are to be studied and/or influenced through management. Specific ecosystem boundaries are based on discontinuities in the geographic distribution of ecosystem characteristics and management jurisdictions. This will lead to specifying ecosystems at a hierarchy of scales with boundaries that sometimes overlap.

What primary issues will be addressed under an EAF? Incorporation of ecosystem-based approaches into fisheries management involves accounting for a number of important classes of interactions that are not routinely evaluated in current species-by-species or fishery-based management programs.

Bycatch or fishery interactions: Bycatch and fishery interactions, including mortalities of non-target species, arise when multiple fisheries share the same species. Discards are usually incorporated into singlespecies stock assessments (when reliable data are available). However, few management programs explicitly consider the total value of the catch from systems of competing fishing activities.

Indirect effects of harvesting: An important class of indirect harvesting effects on ecosystems involves alterations of feeding relationships and energy flows between trophic levels. Negative effects (a 'trophic cascade'; Carpenter 2003) can result if fishing alters the balance between predators and their prey. Indirect effects also include impacts of fishing practices that alter the functional value of vulnerable habitats.

Interactions between biological and physical components of ecosystems: Environmental variation (in trend and amplitude) is an important component that has critical implications for the resilience and productivity of marine ecosystems. Trends in environmental variables (e.g. temperature, other oceanographic attributes) may drive long-term re-structuring of species assemblages, whereas high amplitude variations (e.g. in recruitment) induce local instabilities or distribution shifts of biological components. Regime shifts in biological productivity may occur due to sudden, significant environmental change, or as a result of harvest-induced changes in biological communities (Steele 1998, Scheffer \& Carpenter 2003). The reversibility of regime changes is not guaranteed. Life history, environmental variation and fishing strategies interact in complex ways to affect the stability of biological communities. For example, low rates of harvest may lead to biological community structures that are more resistant to environmental fluctuation, by extending the age profile of long-lived species. 
Each of the above classes of interaction effects may be important when ecosystem objectives associated with them are incorporated into management programs. One type of tool that has been widely proposed as being relevant to an ecosystem approach is Marine Protected Areas (MPAs). Below, we provide some thoughts on the role that MPAs can play in developing ecosystem-based approaches.

MPAs - are they synonymous with an ecosystem approach to fisheries? MPAs and EAF are so often discussed together that one might think they are synonymous (e.g. Botsford et al. 1997, Allison et al. 1998, Palumbi 2002). However, MPAs are just one of a suite of fishery management tools that have merit (and limitations) for either single-species approaches to management, or for ecosystem approaches (EAF). While MPAs are an obvious measure to consider when valuable biological, physical or cultural resources are located in discrete areas, there may be severe downsides to their indiscriminant use (discussed below).

For the most part, MPAs (and other forms of area closures) have been used to (1) control fishing mortality on target species, (2) reduce bycatch and wasteful discards, and (3) protect vulnerable habitats and biodiversity. The relevance of MPAs to these 3 objectives is discussed below.

Controlling the fishing mortality rate on target species: Controlling fishing mortality, and manipulating its application on particular size or age classes, are the keys to achieving the typical objectives of sustainability, high yield, and efficiency. Often, this is done by setting a Total Allowable Catch (TAC) based on the relationship between catch and fishing mortality. Another approach is to limit fishing effort (days at sea or some other effort metric) since fishing mortality is proportional to effort. Controlling fishing mortality through either a TAC or limit on fishing effort requires considerable scientific information about the fishery and resource species. This is the type of information that is routinely collected for fisheries conducted by developed countries, but it is rarely available in developing countries. Even in relatively data-rich situations, TACs and/or effort limits, are sometimes set incorrectly because of limitations in the scientific information to support them or in the governance institutions that utilize such findings. Thus, it is tempting to propose MPAs as a more robust (to scientific uncertainty and management failure) fisheries management approach. This is sometimes referred to as an insurance policy (Lauck et al. 1998, Murray et al. 1999, NRC 1999b, Ward et al. 2001). Of course, one can establish an MPA with little scientific information and expect to constrain fishing mortality to some degree. Similarly, one can use other fishery management tools with little scientific information and achieve some unspecified degree of control over fishing mortality. However, we are aware of no evidence (nor logical reason) to support the conclusion that MPAs will be a more robust tool to control overall fishing mortality than would other methods.

Perhaps more important is the issue of the effectiveness of MPAs. For species that are highly mobile, one would expect MPAs to be quite ineffective. Animals that are protected within the boundaries of MPAs are vulnerable when they migrate out of the protected area-fishing fleets could simply concentrate their effort on the edges to take advantage of these dispersive movements (Gell \& Roberts 2003, Murawski et al. 2004). At the opposite extreme, sessile species may thrive within protected areas, but they may not benefit the fishery since they cannot be caught. Eggs and larvae that drift out of an MPA may serve to repopulate other areas, thus eventually benefiting the fishery. The potential yield from a sessile population straddling both open and permanently closed areas is likely to be lower than it would have been using other means of controlling fishing mortality, since animals in the open areas cannot be fished harder to compensate for the proportion of the population that is unavailable. This is because fishing the fraction of animals in open areas at higher rates could result in growth overfishing and loss of yield potential (e.g. see Hart 2003 for a discussion of these issues relative to the management of sea scallop Placopecten magellanicus on Georges Bank). This phenomenon would also likely apply to some finfish that have limited home ranges (Gell \& Roberts 2003).

For species between the extremes of being sessile and highly mobile, MPAs should be relatively more effective in terms of conservation, with less sacrifice of potential yield. However, to be effective, the area that needs to be protected may be much larger than the $20 \%$ level that has been discussed by some authors. For example, Lauck et al. (1998) show that $50 \%$ or more of a population's range may need to be protected. This point is also illustrated by fisheries management on Georges Bank. Protected areas (referred to as closed areas) have played a critical role in efforts to rebuild depleted groundfish stocks. Clearly, the efforts are working for some species (Georges Bank haddock Melanogrammus aeglefinus, and yellowtail flounder Limanda ferrugineus). However, about $30 \%$ of the most productive fishing grounds had to be closed, and it was still necessary to cut fishing effort by $50 \%$ or more on some species (occurring primarily outside the closed areas) due to excessive fishing capacity and the effects of displaced effort (Murawski et al. 2000).

There also may be economic and social issues that are unique to the use of MPAs as a tool to limit fishing mortality. Since MPAs usually force fishing into areas of lower fish density, the cost per unit of catch may increase. In this context, MPAs are likely to be less effi- 
cient than other measures. In addition, MPAs may lead to disproportionate economic impacts on less mobile and flexible gears and vessels, particularly if they are located inshore where traditional small scale or artisinal fisheries once operated. Nevertheless, all management measures impose costs on the industry, and these costs are usually bourn disproportionately by some sectors.

Reducing bycatch and wasteful discards: Catching and discarding non-target species, or individuals of target species that are too small to be desirable or that are otherwise prohibited, is a widely recognized problem. Discarding wastes production, potentially causes adverse effects on ecosystem function, distorts allocations, and raises ethical and legal concerns. Closing areas to fishing where there is an unacceptable likelihood of undesirable bycatch is a widely used, and often effective, fishery management approach. For example, there are extensive 'rolling' closures off the east coast of the U.S. to reduce harbor porpoise Phocoena phocoena bycatch in gill nets. Similarly, there are exclusion zones in Alaskan waters to reduce trawl-induced bycatch mortalities on crabs, mammals and other species. In the North Sea, the use of species-specific 'boxes' are likewise intended to reduce catches of undersized animals, and for other conservation purposes.

While MPAs can be a useful tool to reduce bycatch and wasteful discarding, there are alternative approaches have been employed. In general, reducing fishing mortality to target rates that are consistent with life history and productivity will reduce bycatch. From a conservation point of view, it seems likely that if the fishing mortality on the target species is limited to a level that produces a relatively high yield on a sustainable basis (such as MSY), then bycatches will not be problematic for co-occurring species with similar life histories (even if they are not targets, and are thus discarded). Of course, this is why bycatch is a threat to long-lived species (such as mammals and turtles), even when the target species is not overfished.

Another way to reduce bycatch and wasteful discarding is by redesigning fishing gear to minimize catches of non-target species. Such 'conservation engineering' is widely used, and sometimes quite successful (e.g. reducing the bycatch of sea turtles caught by fishing vessels targeting shrimp in the Gulf of Mexico, and by pelagic longline fisheries in the northwest Atlantic).

All of these factors make deciding which approach to apply to reduce bycatch complex, and dictated by cumulative costs, benefits and the ability to enforce regulations that will ensure their effectiveness.

Protecting habitat and enhancing biodiversity: It is increasingly recognized that fishing alters habitat and affects biodiversity, directly or indirectly. In some cases, the concern is over habitat of importance to the fished species. Altering this habitat might have adverse impact on future productivity (although there is currently little compelling evidence of this). Fishing may also potentially alter and/or destroy the habitat of non-target species and, thereby, negatively affect biodiversity and biogenic structures. A high-profile example of this is deep/cold-water corals that are vulnerable to destruction by fishing.

MPAs can be useful for protecting habitat and biodiversity. They are most effective when specific and localized areas can be identified where habitats of particular concern are vulnerable to fishing, or where there are biodiversity 'hot spots'. However, a major challenge in using MPAs to protect habitat and biodiversity is the lack of suitable geographically resolved information. Another problem is that we generally lack scientific evidence relating habitat attributes to the productivity of a species. The relationship between biodiversity and ecosystem function is also poorly understood. Nevertheless, it seems prudent to protect the habitat, and biodiversity hot spots, that seem most unique and vulnerable to fishing gear. However, this raises a dilemma: the more advanced we become in mapping habitat and biodiversity, the more we realize that some forms that were once thought rare may actually be common. For example, when we knew little about the distribution of deep/cold-water coralsbelieving that they were relatively rare-it seemed reasonable to protect all of the known areas where they occurred. We now know that deep/cold water corals are more common than previously thought (ICES 2002a,b), and so the question now becomes: what degree of protection is appropriate for them?

The uses of MPAs as a primary management tool to address the issues noted above need to be carefully considered, both in terms of actual benefits and costs (relative to alternative management measures). MPAs may be the only way to achieve some goals. However, the effects on the system of displaced effort may have other, unanticipated, negative impacts.

Conclusions. The EAF is not a revolutionary new type of management scheme that necessarily takes a direction different from the path along which fisheries management has been evolving. It is, however, a much more inclusive approach in terms of the diversity of stakeholder involvement. If management of living resources is to move significantly beyond a focus on high-profile stocks or assemblages of economically important species, then there is a pressing need both for science and governance institutions to evolve. Increasing emphasis on EAF provides a useful bridge between the traditional single-species basis, and 'ecosystem management', which implies considerations of human activities well beyond the scope of most resource-based institutions.

MPAs, and other forms of area closures, are useful tools for managing fisheries, and they will probably 
take on an even greater role under the EAF (NRC 2001). They have a long history as part of the suite of tools used to control fishing mortality, reduce bycatch, and mitigate fishery interactions. However, their use as a management tool is not inherently any more appropriate, nor are some of their limitations any less consequential, under ecosystem versus traditional species-based management approaches.

An EAF and MPAs are not synonymous, nor are they panacea. However, the potential synergism between them is strong. The increasing attention they are receiving is indicative of society's struggle to make wise decisions about diverse human activities that have uncertain consequence for complex marine ecosystems. Ecosystem-based approaches will increasingly be viewed as a mechanism for resolving conflicting objectives arising from the species-by-species approach, and for integration of knowledge from biology, oceanography, economics and other social sciences, law and politics.

Moving from 'intelligent tinkering' to a more direct focus on ecosystem properties and outcomes will necessarily involve closer ties between science and management. Working in concert, science and management need to recognize and incorporate fundamental uncertainties in how biological components are linked and to utilize adaptive strategies intended to delineate between plausible alternatives. In all likelihood, incorporating ecosystem-based approaches will mean that more factors must be explicitly accounted for in management, which will require greater evaluation of potentially conflicting objectives (Sainsbury \& Sumaila 2003). We agree with other reports concluding that the EAF should generally result in more conservative management than would be the case under more traditional paradigms (e.g. NRC 1999b, Anonymous 2000, Hall 1999, Murawski 2000, Sissenwine \& Mace 2003). The primary benefit of an EAF is that it offers a more complete and integrated accounting of the full range benefits and costs to society associated with developing sustainable approaches for living marine resources.

\section{The future of fisheries: from 'exclusive' resource policy to 'inclusive' public policy \\ Dirk Zeller, Daniel Pauly}

\author{
Fisheries Centre, University of British Columbia, \\ 2259 Lower Mall, Vancouver V6T 1Z4, Canada \\ Emails:d.zeller@fisheries.ubc.ca,d.pauly@fisheries.ubc.ca
}

The current state of global fisheries. The reality of global overfishing is now well documented (e.g. Watson \& Pauly 2001a, Pauly et al. 2002, Christensen et al.
2003). Thus, after a brief summary of overfishing, we will discuss what we believe is the more fundamental issue underlying the problem.

The generally invoked causes of global overfishing are: overcapacity and excessive effort by fishing fleets (Garcia \& de Leiva Moreno 2003), driven by subsidies (Munro \& Sumaila 2002) and technology 'stuffing', which increases the ability of fleets to fish in habitats and at depths previously off-limits, and dramatically amplifies the catching ability of gears (Valdemarsen 2001, Garcia \& de Leiva Moreno 2003). This contributes to the problems associated with 'fishing down marine food webs' (Pauly et al. 1998), and removes the last natural refuges for many resource species (Pauly et al. 2002), and 'collateral impacts' in the form of unwanted by-catch and habitat degradation by mobile gears (Chuenpagdee et al. 2003). Until recently, such effects, sometimes likened to using large-scale forest clear-cutting in the pursuit of an industrial-scale deer hunt (Watling \& Norse 1998, Pauly et al. 2002), were not accounted for in assessments and management, nor perceived by the public as having important impacts on ecosystems. In essence, fisheries are actively undermining the resource base underlying their productive capacity - directly through excessive removals, and indirectly through ecosystem modification.

The notion of 'freedom of the seas', introduced to the 'western' world by Hugo Grotius as Mare Liberum, has dominated humanity's approach to ocean use for nearly 400 yr (Russ \& Zeller 2003). Historically, Mare Liberum was intended as freedom of navigation and trade during maritime conflicts between 17th century England and Continental Europe, yet over time was also increasingly interpreted as a 'right to fish' (Russ \& Zeller 2003). It is this perceived 'right' which, in conjunction with modern market economics and taxpayer subsidies, has led to resource over-exploitation (Pauly et al. 2002). Until the late 20th century, much of the world's oceans were freely accessible to anyone wanting to fish. However, given that the majority of marine catches are taken within $200 \mathrm{~nm}$ of coasts (Jennings et al. 2001), one would have assumed that the potential for overfishing would have declined with the introduction of national responsibility via $200 \mathrm{~nm}$ Exclusive Economic Zones (EEZ). Yet, traditional approaches to setting and implementing management policy, based primarily on target species considerations (ignoring ecosystem effects), have failed to prevent stock declines, collapses and fisheries closures.

The way forward. The debate on how to deal with the specifics of overfishing is ongoing. Yet, the solutions are obvious.

(1) Drastically reduce effort and capacity. Many fisheries today suffer from significant overcapacity, with values of 30 to $50 \%$ estimated by Garcia \& de Leiva 
Moreno (2003), and even higher values suggested by, for example, Pauly et al. (2002). Economists argue that capacity reductions are best achieved through reductions of subsidies, and warn that even subsidies used for vessel decommissioning schemes can be negative in their impacts (Munro \& Sumaila 2002).

(2) While technology usually cannot be 'dis-invented', we can mitigate some of the negative effects of the growth in technological capacity and fishing ability by removing a substantial fraction of all habitats from fishing. Thus, we can artificially recreate the natural refuges which are now lost to ecosystems, and which previously provided the key element of their apparent sustainability (e.g. Pauly et al. 2002, Russ \& Zeller 2003). While debate continues on the optimal size and location of no-take zones, a growing consensus points towards extensive networks of protected areas of at least 20 to $30 \%$ of each habitat (e.g. IUCN 2003). Note that benefits of no-take areas extend well beyond those indicated here, both with regards to fisheries as well as non-extractive uses (genetic- and bio-diversity protection, bio-prospecting etc.). In essence, largescale no-take zones are a precautionary ecosystembased management tool par excellence (e.g. Walters 1998, Roberts et al. 2001). It is well recognised, and implicitly understood, that the establishment of such networks has to go hand in hand with overcapacity reductions, in order to avoid effort build-up in the areas still open to fishing.

(3) To address 'collateral impacts', we have to reconsider gear types and their use within an ecosystem framework, rather than target species issues alone. Technological improvements (e.g. bycatch reduction devices), and selective targeting of fishing grounds to reduce bycatch, are helpful in the short term, but not sufficient in the long run. This applies especially to more unselective mobile bottom gears, especially bottom trawls (Watling \& Norse 1998, Chuenpagdee et al. 2003). The continued use of gears that inflict 'collateral impacts' also highlights the need for extensive networks of no-take areas and use-specific ocean zoning to mitigate these effects at an ecosystem scale (Chuenpagdee et al. 2003, Russ \& Zeller 2003).

Science, management and inclusive public policy. If we are serious about implementing strategic solutions such as those outlined above, and hence move from the traditional focus on single-species to a precautionary ecosystem-based management, a fundamental shift in the governance of ocean resources will have to take place (Pauly et al. 2002, Russ \& Zeller 2003). In the governance context, the deeper problem underpinning the fisheries crisis is neither a failure of science (despite the often used excuse provided by 'uncertainty'), nor one of management; rather it is a problem of public policy (Pauly \& Zeller 2003). This relates to the domi- nant political role played, during management and catch allocation debates, by the users of the resource (i.e. the fishing industry, explicitly seen as 'client' by regulatory agencies) versus the true owners, the present and future citizens of those countries whose stocks are being fished (Macinko \& Bromley 2002). Moreover, our heavy reliance on the concept of 'sustainability', which is often the legally enshrined goal of fisheries management, should be re-examined. Most optimistically, this concept implies maintenance of resource biomasses at current levels, usually much below any levels optimizing productive potential. More pessimistically, it implies a continuous erosion of the resource base (Pauly \& Zeller 2003). Hence, we need to consider 'ecosystem rebuilding', rather than 'sustainability', as a default policy goal (Pitcher 2001).

In the long term, the changes called for above can only come about if the often politically 'exclusive' resource policy structure is altered to an 'inclusive' public policy with active participation by all stakeholders, including extractive and non-extractive interests. However, by default, overriding precautionary consideration must be given to the long-term interests of future generations. This implies the need for economic discounting practises that consider intergenerational equity, which accounts for the economic benefits of conserving resources (Sumaila \& Walters 2004). Central to this shift is the realisation that fishing is a 'privilege' granted to fishers by society. Thus, fishing is not a 'right' in the enforceable sense normally accorded to this word (see Macinko \& Bromley 2002). However, given that 'carrots' work better than 'sticks', we argue-as do others (e.g. Hilborn et al. 2003) — that positive incentives in an 'inclusive' public policy and governance framework are essential.

Unlike any other industrial-scale economic activity that humanity engages in, fishing is embedded in the high and inescapable uncertainty underlying natural marine systems, and our ability to understand and predict them (e.g. Walters 1998). Often ignored is the fact that fishing is not an agricultural activity, but rather the only industrial-scale form of hunting wildlife, which has important (but mostly ignored) consequences for management. Foremost, it requires a precautionary approach and, as an expression of society's ownership, the predominance of the public in policy debate. Indeed, reclaiming the ocean and its resources from excessive use will be a key task for humanity in the 21st century. This requires that information on the state of marine ecosystems and resources be widely available, and in a form accessible to the lay public.

Information access and distribution. 'Wissen ist Macht' (knowledge is power) is as crucial today as it was in the late 19th century when it was a rallying cry for political engagement in Germany (von Rüden \& 
Koszyk 1979). Examples also abound of the natural sciences being perceived as empowering, notably in Victorian England, where scientists such as T. H. Huxley regularly conveyed scientific insights to working class audiences (Desmond 1997). Public knowledge and the empowerment it bestows are particularly critical today, when we are witnessing some of the most extensive, and threatening, human induced changes to global ecosystems. Informing the true owners of marine resources, i.e. the public, and the law makers that represent them, about the impact of fisheries on ocean 'health' is often difficult. A strong lobby exists which, similar to the Tobacco Institute with regard to the effects of smoking, challenges the obvious to maintain the unacceptable (Pauly \& Zeller 2003). This, in turn, requires that knowledge and information are transparent, accessible, freely available and compelling. Only then can an informed public engage in the decision making process as the major stakeholder with respect to their resources. This would ultimately lead to a modern form of community control, the contemporary equivalent of historical practises in, for example, parts of the Pacific (e.g. Johannes 1978). An example of the potential for success in such an approach is the compelling case of Rachel Carson's Silent Spring which, via its public impact, affected policy on pesticide use (Carson 1962). A step in this direction with regard to the effects of fisheries is attempted in Pauly \& Maclean (2003).

The growing scientific knowledge on the effects of fishing on marine ecosystems needs to be made available in outlets other than the peer-reviewed specialist literature or government reports, neither of which are easily accessible for public scrutiny. This information should be synthesized and presented in a readily understood form, and not shrouded in technical jargon. Such public outreach must become part of our work, whether we engage in it directly or indirectly, with the help of the communication professionals available at many research institutions. And given today's wired world, one of the best media for dissemination of such information is the World-Wide-Web.

There are few examples of web-based vehicles for the presentation and dissemination of scientific knowledge. The web sites of most research groups emphasize only their existence and describe the minutiae of their activities. However, the Sea Around Us project at the University of British Columbia Fisheries Centre aims to provide an integrated analysis of the largescale impacts of fisheries on marine ecosystems, and encourages direct information and data-accessibility through its data-oriented front-end web-structure (see www.seaaroundus.org). The project utilizes largescale time series datasets, such as the United Nations Food and Agriculture Organization (FAO) global fisheries landings data (1950-present), and facilitates the development of complementary data series and approaches. Findings from the project are rooted in peer-reviewed outputs to ensure scientific accountability. However, emphasis is also placed on presenting, via the web, public-oriented information on the effects of fishing on ecosystems at a large spatiotemporal scale, through conceptually clear and graphically compelling presentations. Importance is placed on being as jargon-free as possible, e.g. through the use of common names. Time series of fisheries catches extracted from the waters now encompassed within the EEZ of a given country can be viewed by common or scientific names, or by countries fishing within these waters based on a fishing access agreement database that is also accessible. Additional outputs include animated catch, biomass and primary productivity maps that are visually compelling and easily understood (Watson et al. 2003), and soon will include economic outputs, notably catch value. Underlying data sources and background information are readily accessible, included via links to associated databases. Outputs from this project have already yielded important results (e.g. Watson \& Pauly 2001b, Pauly et al. 2002, Christensen et al. 2003, Pauly \& Maclean 2003), including, for example, the FAO itself acknowledging the problem of reliability of fisheries statistics reported to it by member countries. This has lead to a revision of global fisheries catches, identifying a downward trend in per capita food supply (see www.fao.org/fi/statist/nature china/30jan02.asp). The public and media attention attracted by the 'compelling and easily understood maps' (Hall 2004) accompanying much of the project output has the potential to feed directly into the policy debate called for above.

However, besides being anchored in peer-reviewed literature, this knowledge must also be made available offline, i.e. in general interest scientific/nature magazines (e.g. Watson \& Pauly 2001a, Pauly \& Watson 2003). These, and other contributions using such media (e.g. Safina 1995) and the general press (e.g. Broad \& Revkin 2003) have increased interest by the public in marine ecosystems and fisheries issues, and are encouraging. Clearly, as 'seekers of knowledge', scientists should feel compelled to contribute the results of their investigations in a manner accessible to all of society.

Biodiversity databases as information systems. Other examples of the usefulness of online knowledge dissemination relate to the growing need for public understanding of biodiversity issues. For example, Fish Base (Froese \& Pauly 2000, see www.fishbase.org), presents key nomenclatural, distributional, biological and other information for all the over 28000 extant species of finfish. It is maintained by a team of special- 
ists who extract and standardize data from scientific publications. FishBase encourages contributions from the scientific community, in close collaboration with a global network of experts on various taxa and topics. It also provides access to more than 1.5 million records in over 30 other distributed databases, and acts as an electronic archive for historical datasets. FishBase now receives over 10 million hits per month from a wide variety of users from all over the world, thus demonstrating beyond doubt that there is substantial public interest in scientific information if it is presented in a user friendly manner.

However, ecosystems and fisheries are not comprised only of fishes. Hence, other taxonomic groups and data-sources also need to be considered, e.g. through joint initiatives such as the standardization and cross-linking of existing databases, as now achieved by linking the Sea Around Us database with the cephalopod database CephBase (see www. cephbase.org). Alternatively, new biodiversity data sources need to be created, such as the Scientific Expeditions Database being developed by M. L. D. Palomares, parts of which are currently accessible through FishBase. Such historic information, together with long-term data sets as derived from surveys (e.g. http://ram.biology.dal.ca/ myers/welcome.html), provide crucial historical baselines to inform public policy debate. Such information also counters the 'shifting baseline syndrome' (Pauly 1995), which describes humanity's general inability to fully understand the changes our actions have caused, once these changes are outside the observers generational memory. This implies that we do not readily appreciate what ecosystems were like on timelines outside of our personal experience.

Dealing with denial. Debate and critical evaluation of scientific investigations are an integral and valuable part of science, leading to improved insights into natural processes and contributing to scientific consensus. As mentioned above, the real problems arise from denying the obvious in order to maintain a status quo that benefits only a few. The most obvious recent example is that of B. Lomborg, whose self-serving argumentation about an environmental 'litany' in the Skeptical Environmentalist (Lomborg 2001) has been shown, by recognised experts in their field (see e.g. Grubb 2001, Pimm \& Harvey 2001), to be a misleading, superficial treatment of environmental issues, founded on misrepresentation and selective quotations from the literature. This is also true for Lomborgs' treatment of fisheries (Pauly 2002), which includes, for example, the assertion that marine products provide a vanishingly small percentage of global protein intake, clearly ignoring the utter dependence on cheap fish by millions of people in developing countries, whose marine resources are increasingly exploited by distant-water fleets from developed countries, with little economic or food-security returns (Kaczynski \& Fluharty 2002).

With regards to fisheries and the need for ecosystembased management, the existence of overfishing is not disputed by the scientific community (as mentioned earlier), although specific aspects of the problem might be argued about as part of normal scientific debate (Hilborn et al. 2003). The real problem is not the technical quibble over the magnitude of decline in a stock or degradation of ecosystems, but rather the more fundamental problem of fisheries being a force exerting pressure on stocks and disturbing ecosystems, all with little or no 'counter-weight'. The recent trend towards evaluating fisheries in a conservation context, such as the growing influence of endangered species legislation and non-extractive interests in fisheries management, are examples of 'counter-weights' that may lead to more precaution and balance.

Putting fisheries in their ecosystem context. No one seriously argues that ecosystem-based management is about abandoning traditional single-species stock assessments. Indeed, most modeling approaches providing ecosystem-based information for improving fisheries management and re-building ecosystems rely on single-species assessments as a sizeable part of their input data (e.g. Christensen et al. 2003). Nor is ecosystem-based management only about thoughtlessly setting up no-take marine reserves, leading to the common accusation that all this would do is concentrate the same fishing effort into the remaining, reduced fishing areas (Hilborn 2003). Such oversimplified arguments completely miss the major point of the solutions offered by proponents of ecosystem-based management. Put simply, the point is that the various factors act in combination, and need to be addressed as such-combined-and, hence, ecosystem based. To achieve this requires a truly 'inclusive' public policy environment, leading to better governance of these public resources (i.e. the ecosystems) than is currently the case with most fisheries around the globe.

Acknowledgements. We thank our colleagues of the Sea Around Us Project for discussions and comments. We acknowledge the support of The Pew Charitable Trusts, Philadelphia, for initiating and funding the Sea Around Us Project.

\section{LITERATURE CITED}

Agardy T (2000) Effects of fisheries on marine ecosystems: a conservationist's perspective. ICES J Mar Sci 57:761-765

Allison GW, Lubchenco J, Carr MH (1998) Marine reserves are necessary but not sufficient for marine conservation. Ecol Appl 8(Suppl):S79-S92

Andersen KP, Ursin E (1977) A multispecies extension to the Beverton and Holt theory of fishing with accounts of 
phosphorus circulation and primary production. Medd Dan Fisk Havunders 7:319-435

Anonymous (2000) Governance for a sustainable future. II. Fishing for the future. World Humanity Action Trust, London

Balmford A, Bruner A, Cooper P, Costanza R and 15 others (2002) Economic reasons for conserving wild nature. Science 297:950-953

Barton J (2002) Fisheries and fisheries management in Falkland Islands conservation zones. Aquat Conserv Mar Freshw Ecosyst 12:127-135

Beaugrand G, Brander KM, Lindley JA, Souissi S, Reid PC (2003) Plankton effect on cod recruitment in the North Sea. Nature 426:661-664

Botsford LW, Castilla JC, Peterson CH (1997) The management of fisheries and marine ecosystems. Science 277 : 509-515

Botsford L, Micheli F, Hastings A (2003) Principles for the design of marine reserves. Ecol Appl 13(Suppl):S25-S31

Brander K (1981) Disappearance of common skate, Raia batis, from the Irish Sea. Nature 290:48-49

Broad WJ, Revkin AC (2003) Has the sea given up its bounty? The New York Times, 29 July, New York

Brodziak J, Link J (2002) Ecosystem-based fishery management: what is it and how can we do it? Bull Mar Sci 70: $589-611$

Broughton JM (1997) Widening diet breadth, declining foraging efficiency, and prehistoric harvest pressure: ichthyofaunal evidence from the Emeryville Shellmound, California. Antiquity 71:845-862

Caddy JF (2004) A collective responsibility: the integrated roles of managers, scientists and stakeholders in the restoration and management of marine fisheries. Philos Trans R Soc Lond Ser B Biol Sci (in press)

Caddy JF, Agnew D (2003) A summary of global stock recovery plans for marine organisms, including indicative information on the time to recovery, and associated regime changes that may affect recruitment and recovery success. ICES CM 2003/U:08

Carpenter SR (2003) Regime shifts in lake ecosystems: pattern and variation. In: Kinne O (ed) Excellence in ecology, Book 15. International Ecology Institute, Odendorf/Luhe

Carson R (1962) Silent spring. Houghton Mifflin, Boston, MA

Casey JM, Myers RA (1998) Near extinction of a large, widely distributed fish. Science 281:690-692

Castilla JC, Fernández M (1998) Small-scale benthic fishes in Chile: on co-management and sustainable use of benthic invertebrates. Ecol Appl 8(Suppl):S124-S132

Christensen V, Guénette S, Heymans JJ, Walters CJ, Watson R, Zeller D, Pauly D (2003) Hundred-year decline of North Atlantic predatory fishes. Fish Fish 4:1-24

Chuenpagdee R, Morgan LE, Maxwell SM, Norse EA, Pauly D (2003) Shifting gears: assessing collateral impacts of fishing methods in US waters. Front Ecol Environ 1: $517-524$

Cloern JE (2001) Our evolving conceptual model of the coastal eutrophication problem. Mar Ecol Prog Ser 210:223-253

Cochrane KL (2000) Reconciling sustainability, economic efficiency and equity in fisheries: the one that got away? Fish Fish 1:3-21

Cochrane K (2004) The rising tide of fisheries instruments and the struggle to keep afloat. Philos Trans R Soc Lond Ser B Biol Sci (in press)

Collie JS, Hall SJ, Kaiser MJ, Poiner IR (2000) A quantitative analysis of fishing impacts on shelf sea benthos. J Anim Ecol 69:785-798

Conser RJ, Hill KT, Crone PR, Lo NCH, Bergen D (2002)
Stock assessment of Pacific sardine with management recommendations for 2003. Pacific Fishery Management Council, Portland, OR

Constable AJ, de la Mare WK, Agnew DJ, Everson I, Miller D (2000) Managing fisheries to conserve the Antarctic marine ecosystem: practical implementation of the Convention on the Conservation of Antarctic Marine Living Resources (CCAMLR). ICES J Mar Sci 57:778-791

Cortés E, Brooks L, Scott G (2002) Stock assessment of large coastal sharks in the U.S. Atlantic and Gulf of Mexico. Sustainable Fisheries Division Contribution No. SPD-02/ 03-177. NOAA Fisheries, Miami, FL

Cunningham CL, Butterworth DS (2004) Base case Bayesian assessment of the South Africa sardine resource. Marine Resource Assessment and Management Group, University of Cape Town. WG/PEL/APR04/02

Cury P, Shannon LJ (2004) Regime shifts in upwelling ecosystems: observed changes and possible mechanisms in the northern and southern Benguela. Progr Oceanogr (in press)

Cury P, Bakun A, Crawford RJM, Jarre-Teichmann A, Quiñones RA, Shannon LJ, Verheye HM (2000) Small pelagics in upwelling systems: patterns of interaction and structural changes in 'wasp-waist' ecosystems. ICES J Mar Sci 57:603-618

Cury P, Shannon L, Shin YJ (2003) The functioning of marine ecosystems: a fisheries perspective. In: Sinclair M, Valdimarsson G (eds) Responsible fisheries in the marine ecosystem. FAO, Rome, \& CABI Publishing, Wallingford, UK, p 103-123

Dayton PK, Thrush SF, Agardy MT, Hofman RJ (1995) Environmental effects of marine fishing. Aquat Conserv 5: 205-232

Desmond A (1997) Huxley: from devil's disciple to evolution's high priest. Perseus Books, Reading, MA

Dulvy NK, Sadovy Y, Reynolds JD (2003) Extinction vulnerability in marine populations. Fish Fish 4:25-64

Elton C (1927) Animal ecology. Sidgwick \& Jackson, London

FAO (1995a) Code of conduct for responsible fisheries. FAO, Rome

FAO (1995b) Precautionary approach to fisheries. Part 1. Guidelines on the precautionary approach to capture fisheries and species introductions. FAO Fish Tech Pap 350

FAO (2002a) The state of world fisheries and aquaculture 2002. FAO, Rome

FAO (2002b) Report and documentation of the International Workshop on Factors of Unsustainability and Overexploitation in Fisheries (Bangkok, Thailand, 4-8 February 2002). FAO Fish Rep R672

FAO (2003) Fisheries management 2. The ecosystem approach to fisheries. FAO, Rome

Fisher JAD, Frank KT (2004) Abundance-distribution relationships and conservation of exploited marine fish. Mar Ecol Prog Ser (in press)

Fowler CW, Hobbs L (2002) Limits to natural variation: Implications for systemic management. Anim Biodivers Conserv 25:7-45

Froese R, Pauly D (eds) (2000) FishBase 2000: concepts, design and data sources. ICLARM (updates available at www.fishbase.org), Los Baños, Laguna

Gabriel WL, Mace PM (1999) A review of biological reference points in the context of the precautionary approach. In: Restrepo VR (ed) Proceedings of the fifth national NMFS stock assessment workshop: providing scientific advice to implement the precautionary approach under the Magnuson-Stevens fishery conservation and management act. NOAA Tech Memo NMFS-F/SPO-40, p 34-45

Garcia SM, de Leiva Moreno I (2003) Global overview of 
marine fisheries. In: Sinclair M, Valdimarsson G (eds) Responsible fisheries in the marine ecosystem. FAO, Rome, \& CABI Publishing, Wallingford, UK, p 1-24

Garcia S, Newton C (1996) Current situation, trends and prospects in world capture fisheries. In: Pikitch EK, Huppert DD, Sissenwine MP (eds) Global trends: fisheries management. Proceedings of the symposium Global Trends: Fisheries Management. American Fisheries Society Symposium 20. American Fisheries Society, Bethesda, MD, p 3-27

Garcia SM, Zerbi A, Aliaume C, Do Chi T, Lassarre G (2003). The ecosystem approach to fisheries, Rep. No. 443. FAO, Rome

Gell FR, Roberts CM (2003) Benefits beyond boundaries: the fishery effects of marine reserves. Trends Ecol Evol 18: 448-455

Gilbert DJ, Phillips NL (2003) Assessment of the SNA 2 and Tasman Bay/Golden Bay (SNA 7) snapper fisheries for the 2001-02 fishing year. New Zealand Fisheries Assessment Report 2003/45 Ministry of Fisheries, Wellington, NZ

Gislason H (1994) Ecosystem effects of fishing activities in the North Sea. Mar Pollut Bull 29:520-527

Gislason H, Sinclair M (2000) Ecosystem effects of fishing. ICES J Mar Sci 57:465-791

Grubb M (2001) Relying on manna from heaven? Science 294: 1285-1287

Hall MA (1998) An ecological view of the tuna-dolphin problem-impacts and trade-offs. Rev Fish Biol Fish 8:1-34

Hall SJ (1998) Closed areas for fisheries management-the case consolidates. Trends Ecol Evol 13:297-298

Hall SJ (1999) The effects of fishing on marine ecosystems and communities. Blackwell Science, Oxford

Hall SJ (2004) Perspectives on world fisheries. Trends Ecol Evol (in press)

Halpern BS, Warner RR (2003) Matching marine reserve design to reserve objectives. Proc R Soc Lond Ser B Biol Sci 270:1871-1878

Hare SR, Mantua NJ (2000) Empirical evidence for North Pacific regime shifts in 1977 and 1989. Progr Oceanogr 47:103-145

Hart D (2003) Yield- and biomass-per-recruit analysis for rotational fisheries, with an application to the Atlantic sea scallop (Placopecten magellanicus). Fish Bull (US) 101: $44-57$

Harris M (1998) Lament for an ocean. The collapse of the Atlantic cod fishery: a true crime story. McClealand \& Stewart, Toronto

Harwood J, Stokes K (2003) Coping with uncertainty in ecological advice: lessons from fisheries. Trends Ecol Evol 18: $617-622$

Hedgpeth JW (1977) Models and muddles. Helgol Wiss Meeresunters 30:92-104

Hilborn R (1996) Risk analysis in fisheries and natural resource management. Hum Ecol Risk Assess 12:655-659

Hilborn R (2003) Forum reply to 'Marine reserves: the best option for our oceans?' by E. A. Norse. Front Ecol Environ $1: 497-498$

Hilborn R, Branch TA, Ernst B, Magnusson A, Minte-Vera CV, Scheuerell MD, Valero JL (2003) State of the world's fisheries. Annu Rev Environ Resour 28:359-399

Hilborn R, Stokes K, Maguire JJ, Smith ADM and 13 others (2004) When can marine reserves improve fisheries management? Ocean Coast Manag (in press)

Holling CS (1995) What barriers? What bridges? In: Gunderson LH, Holling CS, Light SS (eds) Barriers and bridges to the renewal of ecosystems and institutions. Columbia University Press, New York, p 3-34
Hoffmann RC (2001) Frontier foods for late Medieval consumers: culture, economy, ecology. Environ Hist 7:131-167

Hoffmann RC (2002) Carp, cod, connections-new fisheries in the medieval European economy and environment. In: Henninger-Voss MJ (ed) Animals in human histories - the mirror of nature and culture. University Press, Rochester, NY, p 3-55

Hughes JD (2001) Environmental history of the world: humankind's changing role in the community of life. Routledge, London

Hutchings JA (2000) Collapse and recovery of marine fishes. Nature 406:882-885

Hutchings JA, Myers RA (1995) The biological collapse of Atlantic cod off Newfoundland and Labrador: an exploration of historical changes in exploitation, harvesting, technology and management. In: Arnason R, Felt L (eds) The North Atlantic fisheries: successes, failures and challenges. Institute of Island Studies, Charlottetown, PEI, p 38-93

Hutchings JA, Walters C, Haedrich RL (1997) Is scientific inquiry incompatible with government information control? Can J Fish Aquat Sci 54:1198-1210

ICCAT (2003) Report of the 2002 Atlantic swordfish stock assessment session. Col Vol Sci Pap ICCAT 55(4):1289-1415

ICES (2001) Report of the Advisory Committee on Ecosystems. International Council for the Exploration of the Sea, Copenhagen

ICES (2002a) Report of the Working Group on Ecosystem Effects of Fishing Activities (WGECO). ICES CM 2002/ ACE:03

ICES (2002b) Report of the Study Group on Mapping the Occurrence of Cold-Water Corals (SGCOR). ICES CM 2002/ACE:05

ICES (2003a) Report of the Advisory Committee on Fisheries Management. International Council for the Exploration of the Sea, Copenhagen

ICES (2003b) Advisory Committee on Fisheries Management (ACFM) Annual Report. www.ices.dk/committe/acfm/ comwork/report/asp/acfmrep.asp

Iles TD (1980) The natural history of fisheries management. Proc N S Inst Sci 30:3-19

Iles TD, Sinclair M (1982) Atlantic herring: stock discreteness and abundance. Science 215:627-633

IUCN (2001) IUCN red list categories: version 3.1. IUCN Species Survival Commission, Gland

IUCN (2003) Recommendations of the 5th IUCN World Parks Congress. World Conservation Union

Jackson JBC, Kirby MX, Berger WH, Bjorndal KA and 15 others (2001) Historical overfishing and the recent collapse of coastal ecosystems. Science 293:629-638

Jennings S, Kaiser MJ (1998) The effects of fishing on marine ecosystems. Adv Mar Biol 34:201-352

Jennings S, Polunin NVC (1996) Impacts of fishing on tropical reef ecosystems. Ambio 25:44-49

Jennings S, Kaiser MJ, Reynolds JD (2001) Marine fisheries ecology. Blackwell Science, Oxford

Johannes RE (1978) Traditional marine conservation methods in Oceania and their demise. Annu Rev Ecol Syst 9:349-364

Johannes RE (2002) The renaissance of community-based marine resource management in Oceania. Annu Rev Ecol Syst 33:317-340

Jones PJS (2002) Marine protected area strategies: issues, divergences and the search for middle ground. Rev Fish Biol Fish 11:197-216

Kaiser MJ, Collie JS, Hall SJ, Jennings S, Poiner IR (2002) Modification of marine habitats by trawling activities: prognosis and solutions. Fish Fish 3:114-136 
Kaiser MJ, de Groot SJ (eds) (2000) The effects of fishing on non-target species and habitats: biological, conservation and socio-economic issues. Blackwell Science, Oxford

Kaczynski VM, Fluharty DL (2002) European policies in West Africa: who benefits from fisheries agreements? Mar Policy 26:75-93

Koslow JA, Boehlert GW, Gordon JDM, Haedrich RL, Lorance P, Parin N (2000) Continental slope and deep-sea fisheries: implications for a fragile ecosystem. ICES J Mar Sci 57:548-557

Larkin PA (1977) An epitaph for the concept of maximum sustained yield. Trans Am Fish Soc 106:1-11

Lauck T, Clark C, Mangel M, Munro GR (1998) Implementing the precautionary principle in fisheries management through marine reserves. Ecol Appl 8:72-78

Law R (2000) Fishing, selection and phenotypic evolution. ICES J Mar Sci 57:659-668

Leopold A (1966) A Sand County Almanac, with essays on conservation from Round River. Ballantine Books, New York

Loehle C (2004) Challenges of ecological complexity. Ecol Complex 1:3-6

Lomborg B (2001) The skeptical environmentalist; measuring the real state of the world. Cambridge University Press, Cambridge

Longhurst AR (1998) Ecological geography of the sea. Academic Press, San Diego

Lotze HK, Milewski I (2004) Two centuries of multiple human impacts and successive changes in a North Atlantic food web. Ecol Appl (in press)

Lubchenco J, Palumbi SR, Gaines SD, Andelman S (2003) Plugging a hole in the ocean: the emerging science of marine reserves. Ecol Appl 13(Suppl):S3-S7

MacCall AD (1979) Population estimates for the waning years of the Pacific sardine fishery. Calif Coop Ocean Fish Investig Rep 20: 72-82

Mace PM (1994) Relationships between common biological reference points used as thresholds and targets of fisheries management strategies. Can J Fish Aquat Sci 51:110-122

Mace PM (1997) Developing and sustaining world fisheries resources: the state of science and management. (Keynote presentation.) In: Hancock DA, Smith DC, Grant A, Beumer JP (eds) Developing and sustaining world fisheries resources: the state of science and management. Proceedings of the 2nd World Fisheries Congress, Brisbane, Australia, 1996. CSIRO Publishing, Victoria, p 1-20

Mace PM (2001) A new role for MSY in single-species and ecosystem approaches to fisheries stock assessment and management. Fish Fish 2:2-32

MacKenzie BR, Myers RA, Bowen KG (2003) Spawner-recruit relationships and fish stock carrying capacity in aquatic ecosystems. Mar Ecol Prog Ser 248:209-220

Macinko S, Bromley DW (2002) Who owns America's fisheries? Island Press, Washington, DC

Mullon C, Cury P, Shannon L (2004) Viability model of trophic interactions in marine ecosystems. Nat Resour Model 17: $27-58$

Munro GR, Sumaila UR (2002) The impact of subsidies upon fisheries management and sustainability: the case of the North Atlantic. Fish Fish 3:1-18

Murawski SA (2000) Definitions of overfishing from an ecosystem perspective. ICES J Mar Sci 57:649-658

Murawski SA, Brown R, Lai HL, Rago PJ, Hendrickson L (2000) Large-scale closed areas as a fisheries management tool in temperate marine systems: the Georges Bank experience. Bull Mar Sci 66:775-798

Murawski SA, Rago PJ, Fogarty MP (2004) Spillover effects from temperate marine protected areas. In: Shipley JB (ed) Aquatic protected areas as fishery management tools. American Fisheries Society, Symposium 42, Bethesda, MD

Murray SN, Ambrose RF, Bohnsack JA, Botsford LW and 15 others (1999) No-take reserve networks: sustaining fishery populations and marine ecosystems. Fisheries (Bethesda) $24: 11-25$

Myers RA, Worm B (2003) Rapid worldwide depletion of predatory fish communities. Nature 423:280-283

Myers RA, Worm B (2004) Extinction, survival, or recovery of large predatory fishes? Proc R Soc Lond B (in press)

NOAA (1999) Ecosystem-based fishery management. A report to Congress by the ecosystem principles advisory panel. NOAA Fisheries, U.S. Department of Commerce, Washington, DC (available at: www.nmfs.noaa.gov/sfa/ EPAPrpt.pdf)

NOAA (2001) 32nd Northeast regional stock assessment workshop (32nd SAW). Stock assessment review committee (SARC) consensus summary of assessments. NEFSC Ref Doc 01-04. NOAA Fisheries, Woods Hole

NOAA (2002) Assessment of 20 Northeast groundfish stocks through 2001: a report of the groundfish assessment review meeting (GARM), October 8-11, 2002. NEFSC Ref Doc 02-16. NOAA Fisheries, Woods Hole

NOAA (2003a) 36th Northeast regional stock assessment workshop (36th SAW). Stock assessment review committee (SARC) consensus summary of assessments. NEFSC Ref Doc 03-06. NOAA Fisheries, Woods Hole

NOAA (2003b) 37th Northeast regional stock assessment workshop (37th SAW). Stock assessment review committee (SARC) consensus summary of assessments. NEFSC Ref Doc 03-16. NOAA Fisheries, Woods Hole

Norse EA, Grimes CB, Ralston S, Hilborn R, Castilla JC, Palumbi SR, Fraser D, Kareiva P (2003) Marine reserves: the best option for our oceans? Front Ecol Environ 1: 495-502

Noss RF, LaRoe ET III, Scott JM (1995) Endangered ecosystems of the United States: a preliminary assessment of loss and degradation. National Biological Service Biological Report 128. United States Geological Survey (USGS), Reston, VA

NRC (1999a) Sharing the fish: toward a national policy on individual fishing quotas. National Academy Press, Washington, DC

NRC (1999b) Sustaining marine fisheries. National Academy Press, Washington, DC

NRC (2001) Marine protected areas: tools for sustaining ocean ecosystems. National Academy Press, Washington, DC

NRC (2002) Effects of trawling and dredging on seafloor habitat. National Academy Press, Washington, DC

OECD (1997) Towards sustainable fisheries: economic aspects of the management of living marine resources. Organisation for Economic Co-operation and Development, Paris

Overholtz W (2000) Atlantic herring. In: Status of fishery resources off the northeastern United States. NOAA Fisheries (available at: www.nefsc.noaa.gov/sos/)

O'Riordan T (2003) Sustaining fish farming. Environment 45:2

Palumbi SR (2001) The ecology of marine protected areas. In: Bertness MD, Gaines SD, Hay ME (eds) Marine community ecology. Sinauer, Sunderland, MA, p 510-530

Palumbi SR (2002) Marine reserves. A tool for ecosystem management and conservation. Pew Oceans Commission Report, Arlington, VA

Parsons TR (2003) Macroecological studies of the oceans. Oceanogr Jpn 12:370-374

Parsons TR, Lalli CM (2002) Jellyfish population explosions: 
revisiting a hypothesis of possible causes. La Mer 40: $111-121$

Pauly D (1995) Anecdotes and the shifting baseline syndrome of fisheries. Trends Ecol Evol 10:430

Pauly D (2002) Review of 'The skeptical environmentalist: measuring the real state of the world.' Fish Fish 3:3-4

Pauly D, Maclean J (2003) In a perfect ocean: the state of fisheries and ecosystems in the North Atlantic ocean. Island Press, Washington, DC

Pauly D, Watson R (2003) Counting the last fish. Sci Am 289: $42-47$

Pauly D, Zeller D (2003) The global fisheries crisis as a rationale for improving the FAO's database of fisheries statistics. In: Zeller D, Booth S, Mohammed E, Pauly D (eds) Western Central Atlantic and Brazil: fisheries catches and ecosystem models in the second half of the 20th century, Vol 11(6). Fisheries Centre Research Reports, Vancouver, p 1-9

Pauly D, Christensen V, Dalsgaard J, Froese R, Torres F (1998) Fishing down marine food webs. Science 279: 860-863

Pauly D, Christensen V, Froese R, Palomares ML (2000) Fishing down aquatic food webs. Am Sci 88:46-51

Pauly D, Christensen V, Guénette S, Pitcher TJ, Sumaila UR, Walters CJ, Watson R, Zeller D (2002) Towards sustainability in world fisheries. Nature 418:689-695

Pauly D, Alder J, Bennett E, Christensen V, Tyedmers P, Watson R (2003) The future for fisheries. Science 302: $1359-1361$

Peters RH (1991) A critique for ecology. Cambridge University Press, Cambridge

Pew Oceans Commission (2003) America's living oceans: charting a course for sea change: summary report: recommendations for a new ocean policy. Pew Oceans Commission, Arlington, VA

Phillips B, Ward T, Chafee C (2003) Eco-labelling in fisheries: what is it all about? Blackwell Publishing, Oxford

Pimm S, Harvey J (2001) No need to worry about the future. Nature 414:149-150

Pitcher TJ (2001) Fisheries managed to rebuild ecosystems? Reconstructing the past to salvage the future. Ecol Appl 11:601-617

Policansky D (1998) Science and decision making for water resources. Ecol Appl 8:610-618

Pope JG (1979) A modified cohort analysis in which constant natural mortality is replaced by estimates of predation levels. ICES CM 1979/H:16

Pope JG, Stokes TK, Murawski SA, Iodoine SI (1988) A comparison of fish size composition in the North Sea and on Georges Bank. In: Wolff W, Soeder CJ, Drepper FR (eds) Ecodynamics: contributions to theoretical ecology. Springer Verlag, Berlin, p 146-152

Reiss CS, Panteleev G, Taggart CT, Sheng J, deYoung B (2000) Observations on larval fish transport and retention on the Scotian Shelf in relation to geostrophic circulation. Fish Oceanogr 9:195-213

Rice JC (2003) Environmental health indicators. Ocean Coast Manage 46:235-259

Rice JC (2004) Challenges, objectives and sustainability: benthic communities, habitats and management decision making. Am Fish Soc Symp (in press)

Roberts CM, Andelman S, Branch G, Bustamante RH and 10 others (2003a) Ecological criteria for evaluating candidate sites for marine reserves. Ecol Appl 13(Suppl):S199-S214

Roberts CM, Bohnsack JA, Gell F, Hawkins JP, Goodridge R (2001) Effects of marine reserves on adjacent fisheries. Science 294:1920-1923
Roberts CM, Branch G, Bustamante RH, Castilla JC and 8 others (2003b) Application of ecological criteria in selecting marine reserves and developing reserve networks. Ecol Appl 13(Suppl):S215-S228

Roff JC, Evans SMJ (2002) Frameworks for marine conservation-non-hierarchical approaches and distinctive habitats. Aquat Conserv Mar Freshw Ecosyst 12:635-648

Roman J, Palumbi SR (2003) Whales before whaling in the North Atlantic. Science 301:508-510

Roy C, Weeks S, Rouault M, Nelson G, Barlow R, van der Lingen C (2001) Extreme oceanographic events recorded in the Southern Benguela during the 1999-2000 summer season. S Afr J Sci 97:465-471

Russ GR, Zeller D (2003) From Mare Liberum to Mare Reservarum. Mar Policy 27:75-78

Safina C (1995) The world's imperilled fish. Sci Am 273:46-53

Sainsbury K, Sumaila UR (2003) Incorporating ecosystem objectives into management of sustainable marine fisheries, including 'best practice' reference points and use of marine protected areas. In: Sinclair M, Valdimarsson G (eds) Responsible fisheries in the marine ecosystem. FAO, Rome, \& CABI Publishing, Wallingford, UK, p 343-361

Sainsbury KJ, Punt AE, Smith ADM (2000) Design of operational management strategies for achieving fishery ecosystem objectives. ICES J Mar Sci 57:731-741

Scheffer M, Carpenter SR (2003) Catastrophic regime shifts in ecosystems: linking theory to observation. Trends Ecol Evol 18:648-656

Schiermeier Q (2002) How many more fish in the sea? Nature 419:662-665

Schindler DE, Essington TE, Kitchell JF, Boggs C, Hilborn R (2002) Sharks and tunas:fisheries impacts on predators with contrasting life histories. Ecol Appl 12:735-748

Shanks AL, Grantham BA, Carr MH (2003) Propagule dispersal distance and the size and spacing of marine reserves. Ecol Appl 13(Suppl):S159-S169

Sherman K, Duda AM (1999) An ecosystem approach to global assessment and management of coastal waters. Mar Ecol Prog Ser 190:271-287

Shin YJ, Cury P (2004) Using an individual-based model of fish assemblages to study the response of size spectra to changes in fishing, Can J Fish Aquat Sci 61:414-431

Sinclair M (1988) Marine populations. An essay on population regulation and speciation. University of Washington Press, Seattle, WA

Sinclair M (1992) Population structure and recruitment variability in North Atlantic fish species. In: Hancock DA (ed) 1993. Recruitment processes. Bureau of Rural Resources Proceedings No. 16. Australian Government Publishing Service, Canberra, p 3-10

Sinclair M, Iles TD (1988) Population richness of marine fish species. Aquat Living Resour 1:71-83

Sinclair M, Iles TD (1989) Population regulation and speciation in the ocean. J Cons Cons Int Explor Mer 45:165-175

Sinclair M, Valdimarsson G (2003) Responsible fisheries in the marine ecosystem. FAO, Rome, \& CABI Publishing, Wallingford, UK

Sissenwine MP, Mace PM (2003) Governance for responsible fisheries: an ecosystem approach. In: Sinclair M, Valdimarsson G (eds) Responsible fisheries in the marine ecosystem. FAO, Rome, \& CABI Publishing, Wallingford, UK, p 363-390

Smedbol RK, Wroblewski JS (2002) Metapopulation theory and northern cod population structure: interdependency of subpopulations in recovery of a groundfish population. Fish Res 55:161-174

Smith IWG (2004) Retreat and resilience: fur seals and human 
settlement in New Zealand. In: Monks G (ed) Sea mammals: exploitation and cultural importance. Oxbow, Oxford (in press)

Steele J (1998) Regime shifts in marine ecosystems. Ecol Appl 8(Suppl):S33-S36

Stefansson G (2004) Methods for managing fisheries: can systems be combined to alleviate the effects of uncertainty? Philos Trans R Soc Lond Ser B Biol Sci (in press)

Steneck RS (1997) Fisheries-induced biological changes to the structure and function of the Gulf of Maine ecosystem. In: Wallace GT, Braasch EF (eds) Proceedings of the Gulf of Maine ecosystem dynamics, scientific symposium and workshop, RARGOM Report 91-1. Hanover, NH, p 151-165

Stergiou KI (2002) Overfishing, tropicalization of fish stocks, uncertainty and ecosystem management: resharpening Ockham's razor. Fish Res 55:1-9

Sumaila UR, Walters C (2004) Intergenerational discounting: a new intuitive approach. Ecol Econ (in press)

Tasker ML, Camphuysen CJ, Cooper J, Garthe S, Montevecchi WA, Blaber SJM (2000) The impacts of fishing on marine birds. ICES J Mar Sci 57:531-547

Terceiro M (2003) Stock assessment of summer flounder for 2003. NEFSC Ref Doc 03-09. NOAA Fisheries, Woods Hole

Ulanowicz RE (1993) Inventing the ecoscope. In: Christensen V, Pauly D (eds) Trophic models of aquatic ecosystems, ICLARM Conf Proc 26:9-10

UNDP (2003) Human development report 2003. Oxford University Press, New York

United Nations (1995) Agreement for the implementation of the provisions of the United Nations Convention on the Law of the Sea of 10 December, 1982, relating to the conservation and management of straddling fish stocks and highly migratory fish stocks. United Nations, Rome

Valdemarsen JW (2001) Technological trends in capture fisheries. Ocean Coast Manag 44:635-651

von Rüden P, Koszyk K (eds) (1979) Dokumente und Materialien zur Kulturgeschichte der Deutschen Arbeiterbewegung, 1848-1918. Büchergilde Gutenberg, Frankfurt am Main

Walters C (1998) Designing fisheries management systems that do not depend upon accurate stock assessment. In: Pitcher T, Hart PJB, Pauly D (eds) Reinventing fisheries management. Kluwer Academic Publishers, London, p 279-288

Walters CJ (2003) Folly and fantasy in the analysis of spatial catch rate data. Can J Fish Aquat Sci 60:1433-1436

Watling L, Norse EA (1998) Disturbance of the seabed by mobile fishing gear: a comparison to forest clearcutting. Conserv Biol 12:1180-1197
Ward TJ, Heinemann D, Evans N (2001) The role of marine reserves as fisheries management tools: a review of concepts, evidence and international experience. Bureau of Rural Science, Canberra

Watson R, Pauly D (2001a) Global overfishing. In: Earle S (ed) National Geographic atlas of the ocean: the deep frontier. National Geographic, Washington, DC, p 192

Watson R, Pauly D (2001b) Systematic distortions in world fisheries catch trends. Nature 414:534-536

Watson R, Pauly D, Christensen V, Froese R and 6 others (2003) Mapping fisheries onto marine ecosystems for regional, oceanic and global integrations. In: Hempel G, Sherman K (eds) Large marine ecosystems of the world: trends in exploitation, protection, and research. Elsevier Science Publishers, Amsterdam, p 375-395

Witherell D, Pautzke C, Fluharty D (2000) An ecosystembased approach for Alaska groundfish fisheries. ICES J Mar Sci 57:771-777

Woods J (2004) Predicting fisheries in the context of the ecosystem. In: Beddington J (ed) Theme issue on Fisheries. Philos Trans R Soc Lond Ser B Biol Sci (in press)

Worm B, Myers RA (2003) Meta-analysis of cod-shrimp interactions reveals top-down control in oceanic food webs. Ecology 84:162-173

Worm B, Lotze HK, Hillebrand H, Sommer U (2002) Consumer versus resource control of species diversity and ecosystem functioning. Nature 417:848-851

Worm B, Lotze HK, Myers RA (2003) Predator diversity hotspots in the blue ocean. Proc Natl Acad Sci USA 100: 9884-9888

WSSD (2002) Plan of implementation of the World Summit on Sustainable Development. UN Department of Economic and Social Affairs, Division of Sustainable Development, New York

Zeller D, Pauly D (2001) Visualisation of standardized lifehistory patterns. Fish Fish 2:344-355

The Theme Section may be cited as follows:

Browman HI, Stergiou KI (eds) (2004) Perspectives on ecosystem-based approaches to the management of marine resources. Mar Ecol Prog Ser 274:269-303

Individual contributions may be cited as, e.g.

Lotze HK (2004) Repetitive history of resource depletion and mismanagement: the need for a shift in perspective. In: Browman HI, Stergiou KI (eds) Perspectives on ecosystembased approaches to the management of marine resources. Mar Ecol Prog Ser 274:282-285 